Agrotrópica 31(2): 85 - 102. 2019.

Centro de Pesquisas do Cacau, Ilhéus, Bahia, Brasil

\title{
TRANSFERIBILIDADE E MAPEAMENTO DE MICROSSATÉLITES ENTRE Theobroma cacao L. E Theobroma grandiflorum (WILLD. EX. SPRENG.) SCHUM
}

\author{
Analine dos Santos Nascimento 1 , Rafael Moysés Alves ${ }^{2}$, Carlos Rogério de Sousa Silva ${ }^{3}$, Paulo \\ Sérgio Beviláqua de Albuquerque ${ }^{3}$, Lívia Santos Lima Lemos ${ }^{4}$, Karina Peres Gramacho ${ }^{1,6}$, \\ Didier Clément ${ }^{5,6}$
}

\begin{abstract}
${ }^{1}$ Universidade Estadual de Santa Cruz - UESC. Rod. Ilhéus/Itabuna, km 16 - Salobrinho, 45662-900, Ilhéus - BA. alinemile@hotmail.com; ${ }^{2}$ EMBRAPA Amazônia Oriental - Trav. Dr. Enéas Pinheiro, s/nº, Bairro Marco, 66095-903, CP48, Belém, PA. rafael-moyses.alves@embrapa.br; ${ }^{3}$ CEPLAC-ERJOH, BR 316, km 17, CP 46, Marituba - PA. paulo.bevilaqua@agricultura.gov.br; carlos-roger@ hotmail.com. ${ }^{4}$ Universidade Federal do Sul da Bahia - UFSB Praça Joana Angélica - São José, 45988-058 - Teixeira de Freitas, BA. livia.lemos @ cpf.ufsb.edu.br. ${ }^{5}$ Centre de Coopération Internationale en Recherche Agronomique pour Le Développement (CIRAD-França) CIRAD, UMR AGAP, Avenue Agropolis TA 96/03, 34398 Montpellier, Cedex 5, France; didier.clement@ cirad.fr. ${ }^{6}$ Comissão Executiva do Plano da Lavoura Cacaueira - CEPLAC km 22 Rod. Ilhéus/Itabuna, 45600-970, Ilhéus, BA. gramachokp@ hotmail.com.
\end{abstract}

O gênero Theobroma abrange 22 espécies nativas da região amazônica, dentre elas, duas merecem destaque de produção no Brasil: T. cacao e T. grandiflorum. Devido à importância dessas culturas e a possibilidade de obter informações através de transferibilidade de marcadores moleculares específicos de T. grandiflorum em T. cacao; ii) construir um mapa genético a partir de um cruzamento de T. grandiflorum; iii) posicionar no genoma do cacaueiro os microssatélites de T. grandiflorum. A partir de trabalhos anteriores, foram selecionados e testados 181 marcadores específicos do cacaueiro nos genitores e em cinco indivíduos da população de cupuaçuzeiro, e 44 marcadores específicos do cupuaçuzeiro em cinco genótipos de cacaueiro representativos da diversidade da espécie. As análises de transferibilidade de microssatélites entre $T$. cacao e $T$. grandiflorum mostraram uma baixa taxa de transferibilidade dos marcadores de cacaueiro quando amplificados em cupuaçuzeiro (43,09\%), e uma alta taxa de transferibilidade dos marcadores de cupuaçuzeiro quando amplificados em cacaueiro $(93,3 \%)$. Foi possível obter um mapeamento genético parcial de T. grandiflorum, permitindo flanquear microssatélites, das duas espécies, em sete grupos de ligação do mapa de referência do cacaueiro em um mapa genético consenso da espécie. Os resultados do presente trabalho permitiram obter mais informações sobre a transferibilidade e mapeamento de microssatélites entre $T$. cacao e $T$. grandiflorum. Tais conhecimentos possibilitam estudos posteriores sobre a diversidade genética, caracterização de germoplasma, construção de mapas genéticos e localização de QTLs.

Palavras-chave: Marcadores SSR, Vassoura de Bruxa, QTLs.

Transferability and mapping of microssatellites between Theobroma cacao $\mathrm{L}$. and Theobroma grandiflorum (Willd. Ex. Spreng.) Schum. The genus Theobroma comprises 22 species native to the Amazon region, two of which deserve attention in Brazil: T. cacao and T. grandiflorum. Due to the importance of these cultures and the possibility of obtaining information through the transferability of specific molecular markers and carrying out studies in genetic mapping, this work had as objectives: i) to test the transferability of T. cacao microsatellites in T. grandiflorum, and specific of $T$. grandiflorum in T. cacao; ii) construct a genetic map from a cross of $T$. grandiflorum; iii) to position in the cacao genome the microsatellites of $T$. grandiflorum. From previous studies, 181 specific cacao markers were selected and tested in the parents and in five individuals of the cupuaçu tree population, and 44 cupuaçu - specific markers were evaluated in five cacao genotypes representative of the species diversity. Microsatellite transferability analyzes between T. cacao and T. grandiflorum showed a low transferability of cacao markers when amplified in cupuaçu trees (43.09\%), and a high transferability of cupuaçueiro markers when amplified in cacao ( 93.3\%). It was possible to obtain a partial genetic mapping of T. grandiflorum, allowing flanking microsatellites of the two species in seven linkage groups of the cacao reference map in a genetic consensus map of the species. The results of the present work allowed to obtain more information on the transferability and mapping of microsatellites between T. cacao and T.grandiflorum. Such knowledge enables further studies on genetic diversity, characterization of germplasm, genetic mapping and localization of QTLs.

Key words: SSR markers, witches' broom, QTL's 


\section{Introdução}

Theobroma cacao L. e Theobroma grandiflorum (Willd. ex. Spreng.) Schum são duas das espécies mais exploradas da família Malvaceae, são diplóides $(2 \mathrm{n}=20$ cromossomos) e perenes (Alves et al., 2007). Theobroma cacao L. é considerada uma das fontes de renda de pequenos e grandes produtores agrícolas devido ao seu produto final, o chocolate, que nas últimas décadas do século passado foi considerado um dos motores da economia do Brasil e outros países, como a Costa de Marfim, primeiro produtor de cacaueiro no mundo (ICCO, 2014).

Theobroma grandiflorum é nativo da região Amazônica, onde se encontra amplamente distribuído. Foi também introduzido na região da Mata Atlântica principalmente no Sul da Bahia, onde vem ganhando destaque no panorama agrícola e econômico do país decorrente do crescente consumo de sua polpa para fabricação de produtos alimentícios como sucos, sorvetes, geleias, sendo também explorado pela indústria de cosméticos (Alves et al., 2007). Estas características somadas ao fácil manuseio, industrialização e abertura do mercado às frutas exóticas, vêm despertando acentuado interesse não só do mercado regional, bem como, abrindo caminhos para exportação nacional e internacional. Destaca-se nesse mercado o estado do Pará, que é responsável pela maior produção do fruto no país (Homma, Carvalho e Menezes, 2001).

A conservação dos recursos genéticos das espécies amazônicas do gênero Theobroma é de fundamental importância uma vez que consiste no reservatório de genes para a espécie T. cacao. Atualmente os dois principais bancos ativos de germoplasma de espécies afins ao cacaueiro são a coleção "George Basil Bartley”, pertencente à Comissão Executiva do Plano da Lavoura Cacaueira- CEPLAC no município de Ananindeua - Pará e a coleção "George Addison O’Neill” pertencente a Embrapa Amazônia Oriental CPATU, na cidade de Belém - Pará. O Banco Ativo de Germoplasma do Cacaueiro é situado nas dependências da CEPLAC - CEPEC, no município de Ilhéus, Bahia e na Amazônia na CEPLAC - ERJOH, os quais complementam-se, possuindo acessos coletados no Brasil e de diversos outros Países, possuindo desta forma ampla variabilidade genética.
No fim do século passado, as plantações de Theobroma cacao na Bahia (Pereira et al., 1989) e adjacências sofreram elevadas perdas devido infecção pelo basidiomicota Moniliophthora perniciosa (Aime; Phillips-Mora, 2005), agente causador da Vassoura de Bruxa do cacaueiro. Vários tecidos da planta; ramos, almofadas florais, flores e frutos maduros são infectados pelo patógeno. O crescimento hipertrófico dos meristemas vegetativos infectados, "vassoura", é o sintoma mais característico da doença (Silva et al., 2003). A Vassoura de Bruxa é uma das principais causas do declínio na produção de frutos de cupuaçuzeiro e cacaueiro, chegando a perdas de 20 a $90 \%$ da produção.

A doença é endêmica da planície Amazônica. No Sul Bahia, o primeiro relato da Vassoura de Bruxa em T. grandiflorum ocorreu em meados de 1997 (Lopes, et al., 2001). Vários estudos envolvendo o cupuaçuzeiro estão em andamento com grupos de pesquisas, principalmente na EMBRAPA/CPATU (Belém) responsável pelo programa de melhoramento genético (Alves, et al., 2017, Alves, et al., 2013, Alves, et al., 2007), e EMBRAPA/CENARGEN (Brasília) para os estudos em genômica funcional. Além disso, na Bahia, a CEPLAC - CEPEC e a UESC estão envolvidos em estudos e projetos próprios ou em parceria com a EMBRAPA, para fins de melhoramento da espécie $T$. grandiflorum.

Devido ao grande interesse e importância dessas espécies, torna-se necessário um melhor entendimento dos níveis e distribuição da variabilidade genética. Tais conhecimentos possibilitam estudos posteriores sobre a diversidade genética, caracterização de germoplasma, construção de mapas genéticos e localização de QTLs. Diversas técnicas de biologia molecular estão hoje disponíveis para a detecção de variabilidade genética ao nível das sequências de DNA, dentre elas podemos citar os microssatélites (Simple Sequence RepeatsSSR), que são fragmentos de DNA formados por sequências curtas de dois a cinco nucleotídeos repetidos em tandem, os quais são flanqueados por sequências únicas não repetidas. A variação alélica em locos de microssatélites pode ser facilmente detectada por PCR usando primers flanqueadores específicos (Hancock, 2000).

Em plantas, os microssatélites são muito frequentes e distribuídos ao acaso ao longo do genoma. Atualmente vários locos de microssatélites estão mapeados e 
distribuídos nos 10 cromossomos na espécie T. cacao (Lanaud et al., 1995; Pugh et al., 2004; Brown et al., 2005; Schnell et al., 2007.; Faleiro et al., 2006; Allegre et al., 2011). Uma das principais características dos marcadores microssatélites é a facilidade de serem transferíveis entre espécies estreitamente relacionadas, diante disso, a genômica comparativa tornou-se uma importante estratégia para a utilização de informações genéticas entre diferentes espécies, revelando que o conteúdo e a forma de genes são, geralmente, conservados entre algumas espécies relacionadas.

O método de transferir marcadores SSR de uma espécie para outra, conhecido como transferibilidade de primers ou amplificação cruzada, tem revelado sucesso como no caso da transferência dentro de diferentes famílias de plantas, especialmente nas leguminosas (Kuleung et al., 2004; Peakall et al., 1998). As taxas de amplificação cruzada são maiores quando as espécies são de mesmo gênero, como observado no caso da soja, em que houve $65 \%$ de transferibilidade para espécies de Glicine e apenas 13\% para espécies dos outros gêneros. Esses trabalhos sugerem maior possibilidade de transferência entre espécies do mesmo gênero. Além disso, ressaltam a possibilidade de estudar espécies de menor interesse econômico, que por isso em muitos casos ainda não foram estudadas (Kuleung et al., 2004; Peakall et al., 1998).

A chance de sucesso no uso de transferência de marcadores é inversamente proporcional à distância evolucionária entre as duas espécies. No caso do gênero Theobroma, já foram isolados, sequenciados e avaliados uma grande quantidade de locos, pelo grupo do CIRAD, em Montpellier - França (Allegre et al.,
2011). Foi verificado que primers desenhados para $T$. cacao amplificavam microssatélites de outras espécies do gênero, inclusive o cupuaçuzeiro (Alves et al., 2007). Assim como, também foram testados marcadores específicos do cupuaçuzeiro em genótipos do cacaueiro para fins de estudos de diversidade genética das espécies (Ferraz dos Santos et al., 2016).

Diante desse cenário, este trabalho surgiu como uma das etapas de um projeto maior que visa à construção de um mapa genético de T. grandiflorum. Para tal, esse trabalho teve como objetivos: i) testar a transferibilidade de microssatélites de T. cacao em T. grandiflorum, e específicos de T. grandiflorum em T. cacao; ii) construir um mapa genético a partir de um cruzamento de T. grandiflorum; iii) posicionar no genoma do cacaueiro os microssatélites de $T$. grandiflorum.

\section{Material e Métodos}

\section{Seleção de Genótipos de $T$. grandiflorum e $T$. cacao}

Para realização do mapeamento genético e estudos de transferibilidade de marcadores entre espécies $T$. cacao x T. grandiflorum foi utilizada uma progênie composta por 142 indivíduos da espécie T. grandiflorum originada a partir do cruzamento entre os genótipos CP174 X CP1074, resistente e suscetível à Vassoura de Bruxa, respectivamente, e contrastantes para outras características como tamanho e formato dos frutos (Figura 1). A população está localizada na Estação de Recursos Genéticos José Haroldo - CEPLAC/ERJOH, no município de Benevides, estado do Pará.

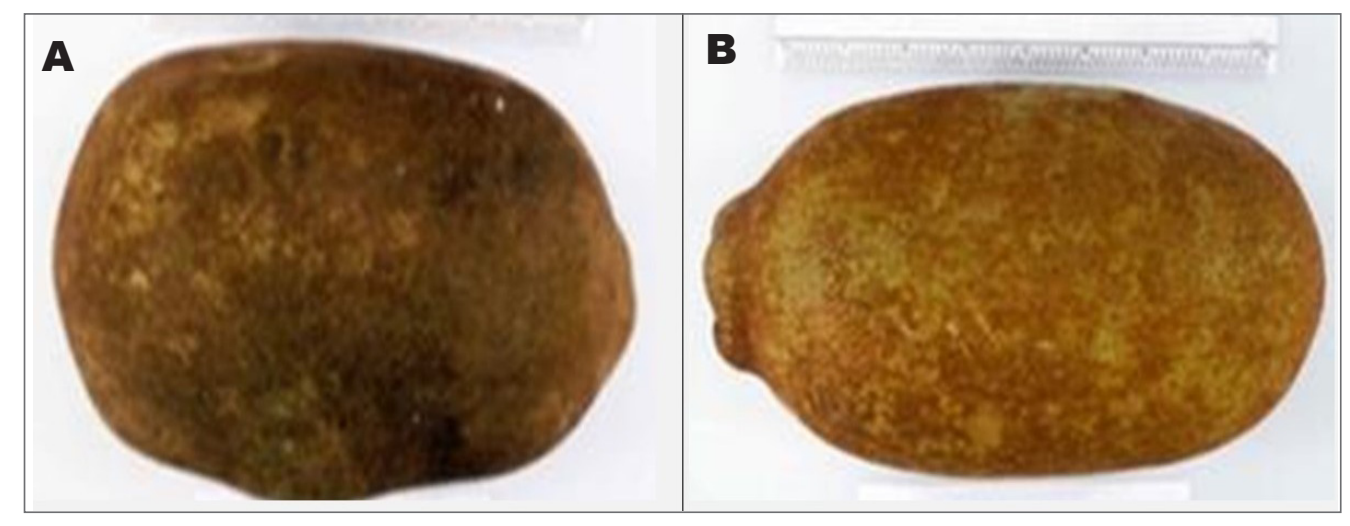

Figura 1. Frutos dos genótipos contrastantes de Theobroma grandiflorum que representam os pais da população utilizada nesse estudo. (A) CP174 resistente, (IB) CP1074 susceptível a doença Vassoura de Bruxa. 
Para os estudos de transferibilidade de marcadores entre as espécies $T$. grandiflorum x $T$. cacao, foi utilizada uma seleção de cinco genótipos de T. cacao (CriolloB97/61/B2, Scavina 6, ICS1, SIC864 e CCN51) contrastantes e representativos da diversidade genética da espécie, conforme trabalhos já publicados (Motamayor et al., 2013), cujos indivíduos foram utilizados em cruzamentos para estudos genéticos do cacaueiro como a população F2 resultado da autofecundação de TSH516, oriundo do cruzamento entre Scavina-6 e ICS1 (Faleiro et al., 2006), o CCN51 do Equador e o genótipo Criollo B97/61/B2 de Belize, que foi escolhido por ser puro homozigoto e utilizado para o sequenciamento do genoma do cacaueiro (Argout et al., 2010). Foram coletadas amostras foliares de todos os indivíduos para posterior extração de DNA. Esse material foi cortado em discos foliares, acondicionados em tubos Eppendorf de $2 \mathrm{~mL}$ armazenados em freezer $-80{ }^{\circ} \mathrm{C}$ e liofilizados durante 24 horas antes da extração.

\section{Seleção dos marcadores SSR}

Foram utilizados 44 marcadores microssatélites obtidos para $T$. grandiflorum e determinados como polimórficos nos pais CP174 e CP1074 do cruzamento do cupuaçuzeiro da população acima citada. Dentre estes, 14 SSR/EST foram desenhados pela EMBRAPA/CENARGEN e 30 oriundos da biblioteca SSR feita com DNA genômico (EMBRAPA/CPATU) (Tabela 1). Além desses, 181 marcadores específicos de T. cacao foram escolhidos dos diferentes grupos de ligação do cacaueiro e utilizados para realizar uma triagem dos SSRs polimórficos para os pais CP174 e CP1074. A relação dos SSRs utilizados é apresentada na Tabela 2.

\section{Extração de DNA}

Foram extraídos DNA de amostras foliares de todos os genótipos seguindo o protocolo MATAB (Mixed Alkyl Trimethyl Ammonium Bromide) (Risterucci, 2000). Para verificar a integridade do DNA extraído, uma alíquota de $5 \mu \mathrm{L}$ de cada amostra, adicionada de $3 \mu \mathrm{L}$ do corante tipo IV (Bromofenol Blue a 0,25\%, sacarose $40 \%$ ) e $2 \mu \mathrm{L}$ de gel-red [ $1 \mathrm{ng} / \mu \mathrm{L}$ ], foi aplicada em gel de agarose a $2 \%$, utilizando como tampão de corrida o TAE1X (EDTA 2 mol.L $\mathrm{L}^{-1}$; Tris-acetato 9 mol. $\left.L^{-1}\right)$ para realização de corrida eletroforética em cuba horizontal a 80 volts por $30 \mathrm{~min}$.
Tabela 1. Marcadores moleculares específicos de $T$. grandiflorum (EMBRAPA-CENARGEN e CPATU) utilizados nos testes de transferibilidade com $T$. cacao

\begin{tabular}{|c|c|c|c|}
\hline N. & Nome & Origem & Instituição \\
\hline 1 & cupuaçu_rep_c295 & EST & CENARGEN \\
\hline 2 & cupuaçu_rep_c293_C & EST & CENARGEN \\
\hline 3 & cupuaçu_rep_c180 & EST & CENARGEN \\
\hline 4 & cupuaçu_rep_c432 & EST & CENARGEN \\
\hline 5 & cupuaçu_c4949 & EST & CENARGEN \\
\hline 6 & cupuaçu_rep_c2763 & EST & CENARGEN \\
\hline 7 & cupuaçu_rep_c431C & EST & CENARGEN \\
\hline 8 & cupuaçu_rep_c203_A & EST & CENARGEN \\
\hline 9 & cupuaçu_rep_c203_B & EST & CENARGEN \\
\hline 10 & cupuaçu_rep_c618 & EST & CENARGEN \\
\hline 11 & cupuaçu_rep_c1251 & EST & CENARGEN \\
\hline 12 & cupuaçu_rep_c339 & EST & CENARGEN \\
\hline 13 & cupuaçu_rep_c1773 & EST & CENARGEN \\
\hline 14 & cupuaçu_rep_c733 & EST & CENARGEN \\
\hline 15 & $\operatorname{Tg} 04$ & SSR & CPATU \\
\hline 16 & $\operatorname{Tg} 05$ & SSR & CPATU \\
\hline 17 & $\operatorname{Tg} 09$ & SSR & CPATU \\
\hline 18 & $\operatorname{Tg} 11$ & SSR & CPATU \\
\hline 19 & $\operatorname{Tg} 13$ & SSR & CPATU \\
\hline 20 & $\operatorname{Tg} 17$ & SSR & CPATU \\
\hline 21 & $\operatorname{Tg} 20$ & SSR & CPATU \\
\hline 22 & $\operatorname{Tg} 21$ & SSR & CPATU \\
\hline 23 & $\operatorname{Tg} 30$ & SSR & CPATU \\
\hline 24 & $\operatorname{Tg} 31$ & SSR & CPATU \\
\hline 25 & $\operatorname{Tg} 39$ & SSR & CPATU \\
\hline 26 & $\operatorname{Tg} 43$ & SSR & CPATU \\
\hline 27 & $\operatorname{Tg} 44$ & SSR & CPATU \\
\hline 28 & $\operatorname{Tg} 47$ & SSR & CPATU \\
\hline 29 & $\operatorname{Tg} 48$ & SSR & CPATU \\
\hline 30 & $\operatorname{Tg} 54$ & SSR & CPATU \\
\hline 31 & $\operatorname{Tg} 62$ & SSR & CPATU \\
\hline 32 & $\operatorname{Tg} 64$ & SSR & CPATU \\
\hline 33 & $\operatorname{Tg} 65$ & SSR & CPATU \\
\hline 34 & $\operatorname{Tg} 70$ & SSR & CPATU \\
\hline 35 & $\operatorname{Tg} 71$ & SSR & CPATU \\
\hline 36 & $\operatorname{Tg} 72$ & SSR & CPATU \\
\hline 37 & $\operatorname{Tg} 76$ & SSR & CPATU \\
\hline 38 & $\operatorname{Tg} 77$ & SSR & CPATU \\
\hline 39 & Tg88 & SSR & CPATU \\
\hline 40 & Tg89 & SSR & CPATU \\
\hline 41 & Tg90 & SSR & CPATU \\
\hline 42 & $\operatorname{Tg} 102$ & SSR & CPATU \\
\hline 43 & $\operatorname{Tg} 108$ & SSR & CPATU \\
\hline 44 & $\operatorname{Tg} 113$ & SSR & CPATU \\
\hline
\end{tabular}

Foram extraídas 142 amostras de DNA a partir de aproximadamente $300 \mathrm{mg}$ de tecido vegetal que apresentaram qualidade e integridade satisfatórias para a execução das análises moleculares variando de 200 a $1000 \mathrm{ng} / \mathrm{ul}$ de DNA. A diluição de DNA para execução da etapa molecular obedeceu à proporção 
Tabela 2. Marcadores moleculares específicos de T. cacao utilizados na seleção realizada com os pais (174x1074) e uma parcela da população de $T$. grandiflorum

\begin{tabular}{|c|c|c|c|c|}
\hline Locos & 5'-3' Primer Forward & 5'-3' Primer Reverse & Comprimento $(\mathrm{pb})$ & Temp. Anelam. $\left({ }^{\circ} \mathrm{C}\right)$ \\
\hline$m T c \operatorname{CIR} 10$ & ACAGATGGCCTACACACT & CAA GCA AGC CTC ATA CTC & 208 & 46 \\
\hline$m T c \operatorname{CIR} 17$ & AAG GATGAAGGATGTAAGAGAG & CCC ATA CGA GCT GTG AGT & 271 & 51 \\
\hline$m T c \mathrm{CIR} 25$ & CTT CGT AGT GAA TGT AGG AG & TTA GGT AGG TAG GGT TAT CT & 153 & 46 \\
\hline$m T c$ CIR26 & GCA TTC ATC AAT ACA TTC & GCA CTC AAA GTT CAT ACT AC & 298 & 46 \\
\hline$m T c$ CIR36 & TTAGGTTACTCGTGAATG & АCTCCTCTTGTAGTGTTA & 182 & 46 \\
\hline$m T c$ CIR45 & GTCATTGCTGTGTG & CATAGCATTAACTGTGTCTG & 284 & 51 \\
\hline$m T c$ CIR54 & AACCTCTTGTCACGTTA & GAAGGCATACTTACTACTGT & 165 & 46 \\
\hline$m T c$ CIR64 & GAGAAAGTAAAAGGAGAGAG & TGTTAGAGAAATGAGAAGTG & 167 & 46,5 \\
\hline$m T c$ CIR70 & GGTATGAAGGATTGAGAG & TTCCTATTCGTATTTATGGG & 107 & 44,4 \\
\hline$m$ Tc CIR77 & GTTCTCCCCCACTCTCT & AATAAATAAATAAACAATACG & 287 & 47,8 \\
\hline$m T c$ CIR84 & CATGGGACGCTGCCT & СТСТTATTAАATTGAАTTСТСТ & 136 & 47,1 \\
\hline$m$ Tc CIR105 & GTTTACAACTTATCGCTCTG & AАTTTGTATCCCTTATTATTTA & 201 & 46,1 \\
\hline$m T c$ CIR106 & ACGAAAAATACCCTAAAAA & TGCTGTTGTTGTCTTGCT & 143 & 45,8 \\
\hline$m$ Tc CIR107 & TTGCCTGGAAGAGAGA & GATGGAAAGAGAAATAATAGT & 120 & 46,8 \\
\hline$m T c$ CIR109 & GGAAAGTGTAGGAAAGTAGAC & GGACCAAAAAGAGCATA & 162 & 46,4 \\
\hline$m T c \operatorname{CIR} 110$ & GTGAAAAGTGGGGATTG & TAAAGTAAGAGTGGTGATGGT & 139 & 48,2 \\
\hline$m T c$ CIR113 & GGAAAGTTACAGCAAGAGAGA & ACAAGCCCGGTGAAGG & 142 & 50,7 \\
\hline$m T c$ CIR114 & CAGATGAATGGAATAACTT & GCATGAACACAAACACAC & 207 & 48,7 \\
\hline$m$ Tc CIR126 & ААСТСТСАСТАТСАТССАС & AАCAAАTCATCAАACACTT & 212 & 46,3 \\
\hline$m$ Tc CIR133 & GGATCACATCCGTTTAGA & AATTTCAGCCCTCCAA & 155 & 49 \\
\hline$m T c$ CIR 145 & CAGACTTCCAACTCAAAACT & TGAGAATAGATGGACCGAT & 117 & 49,7 \\
\hline$m T c$ CIR155 & CTTGGACTATTGGAAAAC & AAGGATACAATAAGGTAAATAC & 274 & 46,5 \\
\hline$m T c$ CIR158 & TGTAGGTTATGCAGCGTGTTC & GATGAGGGGTGTAGCTGTTTG & 213 & 50,2 \\
\hline$m T c$ CIR164 & AGAACGGTTCAGGACAATC & AGGACAATGATGAAGAAATAAG & 117 & 49,2 \\
\hline$m$ Tc CIR 187 & TTCACCTAGTGTAATGGTCT & GCAGGCTTCAATTTAGAG & 262 & 49,4 \\
\hline$m$ Tc CIR192 & TCACTTCACAATAATTTCAAG & AAATTGAATTCCAGTTGTAG & 98 & 46 \\
\hline$m T c$ CIR195 & CAAGTTGAATAAAGTCCTAAG & AAAATAAAGAAAATGAAGTAA & 350 & 46,6 \\
\hline$m T c$ CIR212 & GAGAAACACTTCAGGATAC & GTCATTTGGCAGATTTA & 186 & 46,6 \\
\hline$m T c \operatorname{CIR} 216$ & ACTGCCCAGGAATCA & TCTTTGTTTCTGCCTTAT & 158 & 47,4 \\
\hline$m T c$ CIR218 & TGACCAAGGAAGCTCTC & GGTGGGAAAGGTGGTA & 187 & 48,9 \\
\hline$m T c$ CIR221 & ATGTAGTTGGGCTGTGA & TGTTAAGAGGGAAATGAA & 273 & 48,6 \\
\hline$m T c$ CIR226 & TAACCCAAATTCAAAGTC & TTTCAACAGCCTCATCT & 246 & 47,3 \\
\hline$m$ Tc CIR228 & CCCCCTGATACTGTGTG & GAAACCTAATCTCGTAATATGT & 110 & 48,7 \\
\hline$m T c$ CIR231 & AGGAGGAGTTGCTGAA & CAGGTTCCAATTTTGTAT & 226 & 47,3 \\
\hline$m T c$ CIR232 & GCTGTTGTCTACTTTTGAAT & CACCCTTTGAATCAGTCTA & 205 & 49,8 \\
\hline$m T c$ CIR234 & TTGTGTCGGTTTGATTC & GAAAGAGAGGGAAAGTGA & 123 & 48,1 \\
\hline$m T c \operatorname{CIR} 237$ & GAAGACAAGGATGGAGACT & GCAAAGAGAGCAGGAGA & 103 & 50,1 \\
\hline$m T c$ CIR239 & CTCCACAGTCAAAATAACA & TTAAATCCCGCAAAGT & 203 & 47,4 \\
\hline$m T c$ CIR241 & CAGTTGGAGGGCATTT & ACGAGTGAGAGAGTGAAGTT & 146 & 50,2 \\
\hline$m$ Tc CIR247 & САTTTTATAАТTССТTCT & АСАТTСТTТАТTTТСАСТ & 111 & 39,9 \\
\hline$m T c$ CIR253 & TGGCTACTAAACACCTACTA & GGGAGGGGAGTAAGTT & 155 & 45,4 \\
\hline$m T c$ CIR254 & ACAACTCCAAAGAACAAG & GGTAAACCTCGTCATAAT & 198 & 45,3 \\
\hline$m T c \operatorname{CIR} 256$ & AGAAGGGTGTCAACATTA & GAACAGTCAAACATAAGAGTA & 185 & 46,1 \\
\hline$m T c$ CIR258 & TAACTCACAATCCATCAT & ATGGTCATTATCAAAATC & 116 & 44,5 \\
\hline$m T c$ CIR259 & TTTCCTGATTTCCATTA & AGAGGTTCCAAAATACAT & 157 & 45,2 \\
\hline$m T c \operatorname{CIR} 265$ & TGAATGCTGGAAAAATGT & GTGTCTGCTTTGGTTTGT & 246 & 49,2 \\
\hline$m$ Tc CIR272 & TTTGCCTTTCCTTTCT & TTTGTCAATTTGGATAGTG & 258 & 48,5 \\
\hline$m$ Tc CIR277 & ACCAAGATCAAAGTCAAGAA & GATAAGAACCAAGTGAAGAGA & 304 & 50,4 \\
\hline$m T c$ CIR281 & CCGCTGTTTTGGTATTTC & GGATGAGGGGTGGTTG & 194 & 51,4 \\
\hline$m T c$ CIR283 & ATCAATACCCACCACACA & СССтTттсстстTтTтст & 239 & 49,3 \\
\hline$m T c$ CIR285 & TACTACСТCTACССТCTTGT & ATAААТTССТTСССТTCT & 216 & 46,7 \\
\hline$m T c$ CIR288 & ACAACACAAGGCAAAGA & CCCATTTAGCACCAAC & 184 & 48,8 \\
\hline$m T c$ CIR289 & CTTCCGCCACTAATAAA & CTATACATAACAGCAGCCA & 123 & 46,8 \\
\hline$m$ TcCIR 293 & GAAAGGCCATATTGATGCT & СТАТТТССАСАСТСААТТССА & 266 & 55,2 \\
\hline$m T c$ CIR 299 & CCTTTTGTTCCCTTCATTTT & CCGCCTTTCTCTTCTCC & 146 & 55,9 \\
\hline$m$ Tc CIR 302 & CTGTAACCAACCCTAAAGAAAA & AGTTGAATGTTGGCCCTT & 269 & 55,4 \\
\hline$m$ Tc CIR 303 & GGCTTCCAGGCTTTACC & CCACTCCGAAATTCCCT & 258 & 55,8 \\
\hline$m T c$ CIR 310 & GGGGATACTTGACCTCTGTT & GCTGGACCTAAAACGCA & 176 & 55,7 \\
\hline$m T c$ CIR 314 & GGATCTTCAGTCCCCAAA & ATCCAGGTAGAGGAGGAATG & 247 & 55,7 \\
\hline
\end{tabular}


Continuação Tabela 2

\begin{tabular}{|c|c|c|c|c|}
\hline$m$ Tc CIR 315 & CCAAATGTTTCACAAGGG & TCATGCAGCAACAAGAGA & 257 & 54,7 \\
\hline$m$ Tc CIR 318 & TTCGGGGTTCACTTGG & CAGCATCGCACAAGACA & 192 & 56,1 \\
\hline$m T c$ CIR 319 & TCTATTTCTATGATGGTGGTTC & CTGCTTTTGTTGTTGTGG & 204 & 53,4 \\
\hline$m$ Tc CIR 322 & TTACTGTTTCTCACCACTGTTA & CTGCCTTCATTGCATCT & 274 & 52,7 \\
\hline$m T c$ CIR 324 & CGAAACTCTCTTCTTTCGCT & GGCAGTGGGTTGGTTG & 250 & 56,6 \\
\hline$m$ Tc CIR 325 & TCATCACCACCATGACC & TGGTAAACCCTCCCATC & 114 & 53,8 \\
\hline$m$ Tc CIR 327 & TTTGAGTGGAACAATGGC & CCGATCCAAAAGCAAAG & 157 & 55,3 \\
\hline$m T c$ CIR 329 & AACTCAAGAAAACGCAAGG & TGGTCAACAATGGGCTT & 254 & 55,6 \\
\hline$m T c$ CIR 331 & ССССТCCATTTGGTTTC & CATGACCTCCGCCTGT & 222 & 56,2 \\
\hline$m$ Tc CIR 333 & CAGCACCACCCTGAAAA & GGTTTCGGAGAAATGGG & 123 & 56,4 \\
\hline$m T c$ CIR 336 & AGTGGGAGGAACAGTATGCG & TAAACCGTGTCCACCAAACA & 160 & 60,0 \\
\hline mTc CIR 337 & ACGAAGCCGTAACTTGG & TGCAGGACTCTCTGTCACT & 208 & 54,4 \\
\hline$m$ Tc CIR 339 & CCAAGCTCCAAGGAAAC & GTCCCAAGTTCTCCCAA & 153 & 54,0 \\
\hline$m$ Tc CIR 341 & CCGCCGTCTTTCTTCTT & TTTTACCTGGGGTTGGG & 260 & 56,6 \\
\hline$m$ Tc CIR 342 & CCGGAAAACATTGAACAC & TGGGCTCACCCTTTCT & 223 & 54,7 \\
\hline$m$ Tc CIR 343 & GCTTTGCCCTTTCTTCTCT & AGCACTGAACCGAGCAA & 265 & 56,3 \\
\hline$m T c$ CIR 344 & GTGGCAGAAAGCAGGG & GGGAGATGGAAAGGGAA & 240 & 55,9 \\
\hline$m$ Tc CIR 348 & TGTGGCATCCTCAATCC & GGAGGCGAAGAAGAAGG & 261 & 56,0 \\
\hline$m$ Tc CIR 349 & CATGGGAGTTGGAAAAGAA & TTGGATTCGAGGGTGG & 244 & 56,1 \\
\hline$m$ Tc CIR 350 & CGACGACGACAACAACA & AAGGCAGAGGCTGAGGT & 212 & 55,8 \\
\hline$m$ Tc CIR 351 & CCAAAGAAACAGGAAGCAA & GAAGTTAGGGGCATGGG & 270 & 56,4 \\
\hline$m$ Tc CIR 352 & CGATTCTTCCGTTTCCC & CCATCTGTTGCGGTTGT & 151 & 56,4 \\
\hline$m$ Tc CIR 353 & TGAGTTGAATCACTTTGGCT & TGTTGGACGGGTTGTTC & 250 & 56,0 \\
\hline$m T c$ CIR 354 & AACCCCGAAAAGCACATTCT & TTAAGGTCGTCTCCAGCGTT & 272 & 60,4 \\
\hline$m$ Tc CIR 355 & TCTGGTGAAAGAGCGAAA & CAAAGAAAACGGCCAAA & 195 & 30,5 \\
\hline$m T c$ CIR 356 & GGGGTTGCTTTCTGCTT & AAAACTTGGCGGAGGAG & 163 & 56,3 \\
\hline$m$ Tc CIR 358 & TTGTGCTTTGTCGTATGGGA & TTTTTGCTAATTATTCCCAАCTTT & 227 & 58,8 \\
\hline$m T c$ CIR 359 & TCGAGATACGCAAACGAA & TGGACATTGCGAAAACC & 188 & 56,4 \\
\hline$m T c$ CIR 361 & СсCTTCTGTCTCTCTGTCст & GGGTGGAACCTGAAACC & 189 & 56,0 \\
\hline$m$ Tc CIR 363 & CCCAGCCCTCTAAACCT & GCACCCAAATCAAAGGA & 158 & 55,2 \\
\hline$m T c$ CIR 364 & CGCCGATTCTCTCTCCT & CAGTCTCCGACGAACCA & 201 & 56,4 \\
\hline$m$ Tc CIR 366 & GGGAAAACAACAGCAAAA & TTTTGGAGGCTTTGAGG & 190 & 54,6 \\
\hline$m$ Tc CIR 367 & GGAAAACTCTCAATTCTCTCTTC & TGAGTTGTTGGAGGTGGA & 132 & 55,6 \\
\hline$m$ Tc CIR 373 & CAGGTACACTCATGGACTTTT & CAAATGGAAGGATTGGG & 261 & 54,4 \\
\hline$m T c$ CIR 374 & GGGAGTCTCTTTCCTTTCC & ACTCGGAACCCTTAGCAC & 121 & 55,3 \\
\hline$m$ Tc CIR 376 & TTAGAACAATTTGCAGGGGG & TCTCAGGGCAGCACTTTCTT & 199 & 60,0 \\
\hline$m$ Tc CIR 380 & CCCCGGACACCAAAG & CTGAGCTAGTGGCGGTG & 194 & 56,4 \\
\hline$m T c$ CIR 382 & AAAGAGCGAAAGCAGGG & CCACACCAAGGAGCGT & 245 & 56,4 \\
\hline$m T c$ CIR 383 & GGGGCATTTCTCGCT & TGTAGCTTGGGATGGTTG & 150 & 55,4 \\
\hline$m T c$ CIR 384 & TCCGGTGTCTTCATCGT & GGGGAAATGGGAAAAGA & 245 & 55,7 \\
\hline$m$ Tc CIR 387 & CATGACCATTGCTTTCAACTCT & AGCTGCCCGCGTTTT & 221 & 59,1 \\
\hline$m$ Tc CIR 388 & CTCCCGAAATTCCCATC & TTGGGTTCCAGTCAAAGAG & 264 & 56,2 \\
\hline$m$ Tc CIR 390 & TTGACATCTTGTAGCGGG & GGCCCAAAATAAGGGAG & 188 & 55,5 \\
\hline$m$ Tc CIR 391 & GAAAGCTGGCGGTGAA & CGGCTGGCTGTTCTGT & 211 & 56,7 \\
\hline$m$ Tc CIR 392 & GCAGCAACGAGTGTTTCGTA & GGGGGCCGTTATTCTTTTTA & 176 & 60,1 \\
\hline$m T c$ CIR 397 & CGACCAATACGACGAAGA & ATTAACCGCGTTCGATG & 268 & 55,5 \\
\hline$m T c$ CIR 400 & TCAAAACGGGGAACAGA & GTGTGCCGTTGTTTGGT & 276 & 56,0 \\
\hline$m$ Tc CIR 404 & TTCСТTCCAAAGCCCTC & CGAGGCTGCGGATTT & 181 & 56,4 \\
\hline$m$ Tc CIR 413 & GCCCTCCGAAAATCCT & CAACCACGAATCTCCCTT & 232 & 55,9 \\
\hline$m T c$ CIR 414 & TGGATCACATCCCATCAC & TGACGAAAGTGCAAGGAG & 240 & 55,8 \\
\hline$m$ Tc CIR 418 & ATCCAATGCCAAACCTACA & CGAAGCGTATGAGCAGG & 276 & 56,4 \\
\hline$m T c$ CIR 422 & АCАTCСТTTTCTCTGCCTTT & СССТТСССАТСССТСТ & 208 & 55,6 \\
\hline$m$ Tc CIR 423 & TTTGCCAGGAATCTGTTG & CCTTGGGTGGGCTTC & 277 & 55,5 \\
\hline$m T c$ CIR 424 & TCTACCAGTCAAAATGCCC & СТТСССТСАТССССААС & 233 & 56,1 \\
\hline$m T c$ CIR 428 & TGGCTGGTCCCTACCTT & AGACTTGCCCGGTGTTT & 264 & 56,5 \\
\hline$m T c$ CIR 429 & GGGGATACATCTTCTGCTCT & TTTATTGGTTTCCCGTCC & 177 & 55,8 \\
\hline$m T c$ CIR 430 & CGAAGGAAAGGAAGTAGAATAAG & CGTGGCTTCGATGAGTT & 206 & 55,7 \\
\hline$m$ Tc CIR 431 & GCTGCCAATCGTATCCC & TTGGTGAAGCCCTTGGT & 238 & 57,5 \\
\hline$m T c$ CIR 432 & GGGGAACTTGAAACCAAA & CGGTGGTGGCTCTTTC & 227 & 55,9 \\
\hline$m$ Tc CIR 433 & AGCATTTGCCTTCGCTT & TGAAACAGTCCTGCCGA & 220 & 57 \\
\hline$m$ Tc CIR 444 & TGAACCGGATTGTTGGA & GGGACTTAATCTGGACATGC & 125 & 56,8 \\
\hline
\end{tabular}


Continuação Tabela 2

\begin{tabular}{|c|c|c|c|c|}
\hline$m T c$ CIR 446 & TCTCCAAACCCTAGCCC & CATCGTTATCACTGCCCTT & 120 & 56,1 \\
\hline$m T c \operatorname{CIR450}$ & CACTGAAAATACCTTTGGGTT & GGGGACAAAAGGATGAAA & 246 & 55,8 \\
\hline$m T c$ CIR452 & TCCAAACCATACGAAGCA & TACTCCCAGGGCCTTTC & 247 & 56,0 \\
\hline$m T c$ CIR453 & ACACGGGCAATACACCA & AATGGGAACAAGCCCC & 217 & 56,6 \\
\hline$m T c$ CIR454 & TGACACCATGTAGAGATTTGG & TGAGTAGCCCTTTCCTCAA & 272 & 56,0 \\
\hline$m T c$ CIR455 & GCTCAAGATCCAACAACC & TGCTTTTAGCACGAGGA & 143 & 53,7 \\
\hline$m$ Tc CIR457 & TGTTTTGGCTTTGGCTC & TTTCACaGGGTGAGGACA & 233 & 55,6 \\
\hline$m T c$ CIR458 & AAGTAAAGGgTAGGTTTTGTTG & САTTCATATTGTTTстCСCC & 257 & 54,4 \\
\hline$m T c$ CIR462 & GCTCAACACACCATATCCA & ATGTGGcTCCCATATCCT & 243 & 55,2 \\
\hline$m T c$ CIR463 & CCAGTGGTTTAGTCCCAGTT & TTGGCAGATTTTAGAGAGCA & 253 & 56,6 \\
\hline$m T c$ CIR465 & TGCTGTGATGTTGAGAAGG & cTcCCACACTCAGCCC & 230 & 55,6 \\
\hline$m T c$ CIR467 & AAACGGGGAGAGAATACAAG & AGCCCAAGGTTCCAAAG & 273 & 55,8 \\
\hline$m T c$ CIR468 & TGTTTTGGGAAAATGCT & TCACCATCATCACACCC & 279 & 52,2 \\
\hline$m T c \operatorname{CIR} 470$ & TCGATCTCTTTCCATTTTgT & AAAAGGTTGCCCATATCC & 247 & 54,8 \\
\hline$m T c$ CIR471 & AGCTGACTTGGCACCTTT & TGGGTTTGCCATTGTTC & 150 & 55,8 \\
\hline$m$ Tc CIR472 & TGGTGATGCTTTTGGAGA & CACCGCTGTTCTTTTGG & 251 & 56,0 \\
\hline$m T c$ CIR473 & TTTTGAGACACTCCTGGTTC & GCTACCATTTGCTTTAATCCT & 258 & 55,2 \\
\hline$m T c$ CIR476 & TGTGGACCTCGTAGGGA & GTGCAGTGTGCAGGGA & 161 & 55,6 \\
\hline$m T c$ CIR477 & TCTGGAATCAGTAATCAGCAA & СССТcTAGCCTTGCACTC & 166 & 55,9 \\
\hline$m T c$ CIR478 & GACAGGGTCAATCAACACA & AАCСССААССССТСТT & 280 & 55,0 \\
\hline$m T c$ CIR479 & TGTTTAAGTTTGGACAGCA & ACACCTGCCAATACCaA & 217 & 52,6 \\
\hline$m T c \operatorname{CIR} 480$ & CCCTCAAGCATTAAGAAAA & TGTCCTCTGAAAGAGTGGt & 271 & 53,1 \\
\hline$m T c$ CIR482 & ATACCACATCCTCGTATTTT & GTGGCTGGTGTTGaTg & 264 & 51,2 \\
\hline$m T c$ CIR484 & TTAAGATTGTTATTCTCGTGGG & CTTGATTCGCGGTTTTG & 232 & 56,0 \\
\hline$m T c$ CIR485 & GCATCGCATTTGTTCTTG & TTGGGGTCTGTGGTGAG & 214 & 56,2 \\
\hline$m T c$ CIR486 & AATGTgACACCAAATTGTCC & CCATGTGGGTTGAGGAA & 180 & 55,6 \\
\hline$m T c$ CIR487 & TGCAACTTGACCATTCTTT & ATGCACAAGGACAAGCA & 271 & 54,1 \\
\hline$m T c$ CIR488 & TCCACCTCGAAAGAAGAGA & АTTCCСTTGCAGCCTTT & 108 & 55,9 \\
\hline$m T c$ CIR492 & TCACCAGAAATGCCAGAA & GAATGGAgAGGAAGGCAA & 265 & 56,0 \\
\hline$m T c$ CIR493 & TCGCCAAGGTCACTCTAC & TGTCATCTGTGCCATCTCT & 178 & 54,5 \\
\hline$m T c$ CIR496 & ATTCAAATTCGGAAGCCA & CCACTTTGAGCACGGAA & 223 & 58,6 \\
\hline$m$ Tc CIR497 & TGTTCGCCGGAAAATaG & TCCCACCCATCACTCC & 243 & 55,6 \\
\hline$m T c$ CIR499 & GGCATCCTTATCtAGGCAC & AGACGACTGAAGGCCAA & 272 & 54,7 \\
\hline$m T c$ CIR501 & TTGGCTATTTCACCTCCA & TAACGCAACCACAGCAC & 203 & 54,9 \\
\hline$m T c$ CIR503 & CTTCAGCCGTcATGCTC & CCAAAGCCCAAAACCa & 258 & 56,2 \\
\hline$m T c$ CIR505 & GAGCGAAACGTCACAGAA & TCCAATTTCAATCCAGTCC & 202 & 55,7 \\
\hline$m T c \operatorname{CIR} 508$ & ССТCСССАTTTCATGTTT & CGTTGGAACTTTgGTgG & 280 & 55,6 \\
\hline$m T c$ CIR516 & TTATGTGGgCCTTGTGG & GCTCCATTTTCtTCCTTCC & 262 & 56,1 \\
\hline$m T c$ CIR 525 & GGCCAGTTGTTATTTTGTTC & AATGGGGATACACGCAC & 239 & 54,8 \\
\hline$m T c$ CIR526 & CAGTGGATCGAGGGGA & CCGAACCCAGTGACAAA & 228 & 56,0 \\
\hline$m T c$ CIR533 & TCAАТССААСТССТССТС & GAAACTGACAAGCAAAGAAA & 201 & 53,1 \\
\hline$m T c$ CIR534 & TCGAACTTATTGAGCCG & TAGATTGTCGGCATGTGT & 100 & 53,0 \\
\hline$m T c$ CIR535 & GTGTCAACATCCATCTCCC & TGTCGGaGGAATTTATTGG & 279 & 56,0 \\
\hline$m$ Tc CIR536 & TGCAATGGAGGACCAAG & TCCAcACTTTTGCACCC & 217 & 56,3 \\
\hline$m$ Tc CIR537 & TTCGTGCTTTACACACCC & GCCATCATCAACAACTCAA & 236 & 55,4 \\
\hline$m$ Tc CIR538 & AATCTGTCAACATTCATCTGCT & GGTCAAATGTGGCTTCCT & 250 & 56,4 \\
\hline$m$ Tc CIR539 & CAAGTAGAGATTAACCACAATCC & TCGAAGCTCATCCACATC & 170 & 54,7 \\
\hline$m T c$ CIR542 & САCTTCCACAACCCTGAA & TGCTGATCCTCCTCCAC & 279 & 55,2 \\
\hline$m T c$ CIR546 & CACACTTACCCcGcACA & TTCAATTACAGCCCACCAA & 276 & 58,4 \\
\hline$m T c$ CIR548 & TTTGCTTTTсTTTCCCAC & GCTCATTGCCACTCAAA & 106 & 53,7 \\
\hline$m T c$ CIR549 & TGCCAATTCAGACCACA & GGaTGGCTACTTGcTTATTG & 252 & 55,0 \\
\hline$m T c \operatorname{CIR} 550$ & CATGAGGAATGATTGGGA & ACATGCCTgGATTGATTTAC & 231 & 54,9 \\
\hline$m T c$ CIR552 & AAgCCTCCCTTGAAACC & GTTGGAACCTTGGTGGA & 247 & 55,0 \\
\hline$m T c$ CIR554 & GTGGCCTCACTTTtCTCC & ATTCGACGCAGGTTTTG & 273 & 55,5 \\
\hline$m T c$ CIR555 & CacTTGAATGcGGgTGT & TGGAAATGGAGTCGAAAAG & 242 & 56,2 \\
\hline$m T c \operatorname{CIR556}$ & ACACTTATAGACGGAGCACTAAA & CGCTCTTACATTGAAAtcTTG & 259 & 55,1 \\
\hline$m T c$ CIR560 & TAGTCGCACATAGCCGAG & TTGGGAACAAGCCCC & 147 & 55,9 \\
\hline$m T c$ CIR561 & AGGTGAACAAAAGGGCA & CGACCAcCACCATTCtt & 110 & 54,8 \\
\hline$m T c$ CIR563 & TGAAGACCAAGCAAGTCAA & GGCTATCCATGCACTCAA & 200 & 55,3 \\
\hline$m T c$ CIR564 & AGCTTGGGTGACTATGAGAAC & GGAAGAAGGATGGAAGACC & 186 & 55,9 \\
\hline$m T c$ CIR566 & CTCAACACACTTAGCTCAACC & TGAAGAATGTGATTACGAAGG & 211 & 55,1 \\
\hline
\end{tabular}


de 1:100, onde 1 ul de DNA concentrado foi diluído em $99 \mu \mathrm{l}$ de água ultrapura. Foram realizados testes com outras concentrações, porém a que apresentou resultado mais satisfatório, com bandas bem evidentes em gel de agarose foi utilizado como padrão de diluição. Os padrões de bandas obtidos foram avaliados quanto à ocorrência de amplificação e quanto à presença de polimorfismos de DNA.

\section{Amplificação e genotipagem}

Para os primers de cacaueiro, foi utilizada a reação de PCR com volume final de $20 \mu \mathrm{L}$, contendo entre 5 e 10ng de DNA, 0,2 $\mu \mathrm{M}$ de cada primer, $2,0 \mathrm{mM}$ de $\mathrm{MgCl}_{2}$ (Fermentas) 0,2 mM de dNTP 1X de tampão (10X) e 0,5 a $1 \mathrm{U}$ de TaqDNA polimerase (Fermentas). A temperatura de anelamento dos primers foi testada com a utilização de dois protocolos touchdown (TD), como segue: o primeiro composto por 10 ciclos para desnaturação a $94^{\circ} \mathrm{C}$ por 4 minutos, anelamento do primer geralmente entre $60-48^{\circ} \mathrm{C}$ (TD-6048) usando $1^{\circ} \mathrm{C}$ de decréscimo, e extensão a $72^{\circ} \mathrm{C}$ por 1 min e 30 s, e uma extensão final de 4 min a $72^{\circ} \mathrm{C}$. O segundo touchdown segue as mesmas especificações do primeiro com a ressalva de que sua variação de temperatura de anelamento variou entre 55 e $46^{\circ} \mathrm{C}$ (TD-5546).

Os marcadores ESTs de cupuaçuzeiro desenvolvidos pela EMBRAPA/CENARGEN foram amplificados utilizando programa: $96^{\circ} \mathrm{C}$ por $2 \mathrm{~min}, 9$ ciclos para desnaturação a $94^{\circ} \mathrm{C}$ por $45 \mathrm{~s}$, anelamento do primer entre $62-48^{\circ} \mathrm{C}$ usando $0.5^{\circ} \mathrm{C}$ de decréscimo, extensão a $72^{\circ} \mathrm{C}$ por $45 \mathrm{~s}$, seguidos por 30 ciclos a $94^{\circ} \mathrm{C}$ por $45 \mathrm{~s}, 58^{\circ} \mathrm{C}$ por 1 min e $72^{\circ} \mathrm{C}$ por $45 \mathrm{~s}$, finalizando em $72^{\circ} \mathrm{C}$ por $5 \mathrm{~min}$.

Para os marcadores desenvolvidos pela EMBRAPA/ CPATU foi utilizado o mesmo protocolo descrito acima para cacaueiro. Os fragmentos obtidos após amplificação foram quantificados por eletroforese em gel de poliacrilamida denaturante a $6 \%$ corado com nitrato de prata de acordo com Creste et al. (2001) e Gramacho et al. (2007) e em agarose Metaphor 4\% corado em Gel Red.

\section{Avaliação da Transferibilidade de marcadores microssatélites}

Para avaliar a transferibilidade de marcadores entre as espécies foram selecionados marcadores conhecidamente específicos de $T$. cacao numa coleção de microssatélites do CIRAD. Os marcadores foram genotipados em indivíduos de $T$. grandiflorum, conforme tópico disposto acima, e, os marcadores que apresentassem ocorrência de amplificação foram considerados transferíveis, em seguida foi avaliado o padrão disposto nos géis de poliacrilamida ou agarose Metaphor e separados em duas categorias, monomórficos (1 banda de DNA) e polimórficos (2 bandas de DNA) (Figura 2). Os marcadores classificados como polimórficos foram selecionados para as posteriores etapas do trabalho.

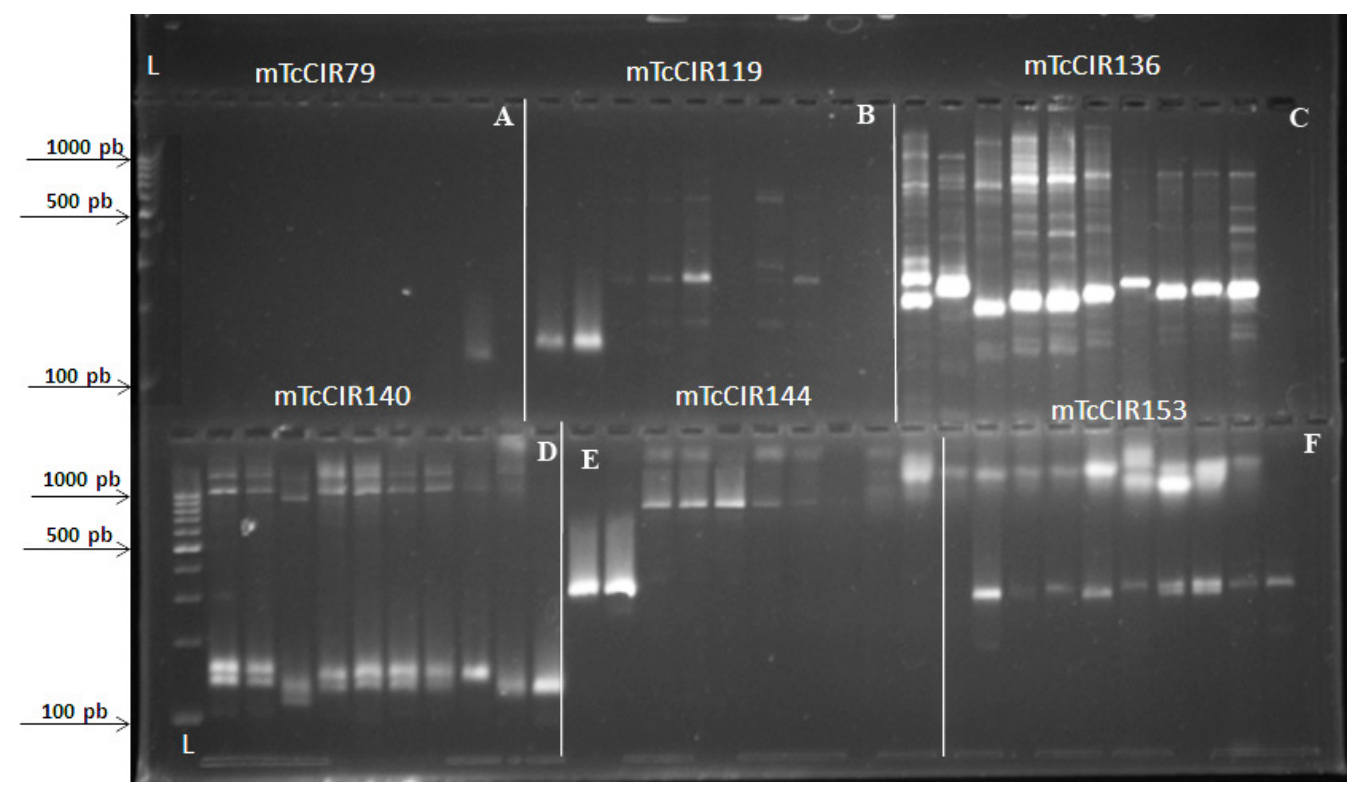

Figura 2. Amplificação de marcadores microssatélites em genótipos do cupuaçuzeiro. (A) marcador mTcCIR79, (B) marcador mTcCIR119. (C) marcador mTcCIR136, (D) marcador mTcCIR140, (E) marcador mTcCIR144, (F) marcador mTcCIR153. 


\section{Mapeamento genético parcial de Theobroma grandiflorum}

O mapa genético parcial da espécie $T$. grandiflorum foi construído utilizando os resultados de genotipagem cedidos pela equipe da EMBRAPA/CEPLAC-CPATU. Uma matriz de genotipagem de 142 indivíduos e 36 SSRs foi utilizada correspondendo respectivamente ao número de plantas vivas quando realizado o último levantamento e o número de SSRs efetivamente polimórficos entre os pais da população (CP174 e CP1074). Para construção do mapa foi utilizado o software JoinMap 4.1 (Van Ooijen, 2006) utilizando-se LOD 3,0 e 4,0 e máximo de $45 \%$ de frequências de recombinação. Foram testadas duas funções de mapeamento, Haldane e Kosambi. O mapeamento foi realizado considerando a população de tipo $\mathrm{CP}$ do JoinMap que significa que a progênie é o resultado do cruzamento entre dois pais heterozigotos com possíveis genótipos como os apresentados na Tabela 3.

Foi realizado um BLAST das sequências dos SSR de $T$. grandiflorum no genoma de T. cacao. Foram utilizados nessa etapa 149 marcadores, onde 135 foram cedidos pelo CPATU, desses 105 foram considerados monomórficos e 30 polimórficos, mais 14 marcadores oriundos do CENARGEN. Estes SSRs foram submetidos à comparação com sequências do genoma do cacaueiro V1 disponíveis na Database (http:// cocoa-genome-hub.southgreen.fr/genome-browser) para o posicionamento no mapa genético físico.

Tabela 3. Descrição da segregação de alelos e possíveis genótipos numa população de tipo CP (Cross Pollinators*)

\begin{tabular}{lll}
\hline Código & \multicolumn{1}{c}{ Descrição da segregação } & \multicolumn{1}{c}{$\begin{array}{c}\text { Genótipos } \\
\text { possíveis }\end{array}$} \\
\hline [ab x bc] & Loco heterozigoto para ambos os pais (4 alelos) & ac ad bc bd \\
{$[\mathbf{e f} \times \mathbf{~ e g}]$} & Loco heterozigoto para ambos os pais (3 alelos) & ee ef eg fg \\
{$[\mathbf{h k} \times \mathbf{~ h k}]$} & Loco heterozigoto para ambos os pais (2 alelos) & $\mathrm{hh} \mathrm{hk} \mathrm{kk}$ \\
{$[\mathbf{l m} \times \mathbf{~ l l}]$} & Loco heterozigoto para o primeiro pai & $\mathrm{lm} \mathrm{ll}$ \\
{$[\mathbf{n n} \times \mathbf{~ n p ]}$} & Loco heterozigoto para o primeiro pai & $\mathrm{nn} \mathrm{np}$ \\
\hline
\end{tabular}

*códigos do programa JoinMap v4.1 (Van Ooijen, 2006), de uma população caracterizada como "crosspollinators".

\section{Resultados e Discussão}

Os genitores da população de T. grandiflorum foram submetidos a um screnning em conjunto com amostras de seis indivíduos da população para encontrar primers que apresentassem: i) transferibilidade entre as espécies, ii) e/ou marcadores polimórficos para construção do mapeamento genético parcial da espécie utilizando o cruzamento CP174xCP1074. Do total de 181 marcadores específicos a T. cacao e testados em $T$. grandiflorum, 78 marcadores amplificaram (43,09\%). Das amplificações, 42 apresentaram polimorfismo $(56,41 \%)$ e os outros 26 foram considerados monomórficos. Os marcadores polimórficos (Tabela 4) foram selecionados para serem genotipados em toda população e mapeados no cruzamento de $T$. grandiflorum.

A baixa taxa de transferibilidade $(43,09 \%)$ dos marcadores de cacaueiro quando amplificados em cupuaçuzeiro pode estar relacionada a diversos fatores, entre eles, a falha na padronização das temperaturas de anelamento dos primers. Foi baixa também a porcentagem de marcadores polimórficos, que pode ser explicado pelo conjunto, quantidade e/ou perfil dos marcadores selecionados para este trabalho sendo insuficiente para diagnosticar com precisão a diversidade genética da população. Foi realizado um segundo screnning com 30 marcadores específicos de cupuaçuzeiro em uma seleção de cinco diferentes genótipos de cacaueiro (Criollo, Scavina 6, ICS1, SIC864 e CCN51) (Tabela 5), para testar a transferibilidade entre espécies. Destes, 28 (93,3\%) foram transferíveis para cacaueiro, dois não amplificaram. Dos marcadores que apresentaram transferibilidade, 10 apresentaram um padrão de alelos homozigotos, $\mathrm{Tg} 05, \mathrm{Tg} 09, \mathrm{Tg} 11$, Tg20, Tg30, Tg48, Tg76, Tg88, Tg108 e Tg113 o que corresponde a $35,71 \%$. Os genótipos que apresentaram maior taxa de transferibilidade foram o Criollo e o Scavina6, e o genótipo que apresentou menor taxa de transferibilidade foi o CCN51. O mesmo teste foi realizado com 14 marcadores cedidos pelo CENARGEN e o resultado mostra que nove deles amplificaram em cacaueiro apresentando diferentes alelos (Tabela 5, Figura. 3), o que era esperado, uma vez, que se trata de variedades da mesma espécie, provenientes de clones geneticamente diferentes. O experimento mostrou ainda, que a taxa de polimorfismo foi baixa, com apenas dois marcadores polimórficos: o c_180 e o c_1251. 
Tabela 4. Relação dos marcadores específicos do cacaueiro polimórficos em T. grandiflorum com as sequências (forwarde/reverse), tamanho esperado em pares de bases (pb), motifs de repetição, temperatura de Melting $\left(\mathrm{Tm}{ }^{\circ} \mathrm{C}\right)$ e grupo de ligação (LG) em que está localizado no mapa genético de $T$. cacao.

\begin{tabular}{|c|c|c|c|c|c|c|}
\hline $\begin{array}{c}\text { Locos } \\
\text { microssatélite }\end{array}$ & 5'-3' Forward primer & 5'-3' Reverse primer & T. E. (pb) & Repetição & $\mathbf{T m}\left({ }^{\circ} \mathbf{C}\right)$ & $\begin{array}{c}\text { Grupo de } \\
\text { Ligação }\end{array}$ \\
\hline mTcCIR85 & TTGAAGTAGAGAGTTGTAAGAA & TTATGGTGTTGGTTGTGAT & 211 & $(A G) 16$ & 46,7 & 1 \\
\hline mTcCIR113 & GGAAAGTTACAGCAAGAGAGA & ACAAGCCCGGTGAAGG & 142 & $(\mathrm{AG}) 9$ & 50,7 & 7 \\
\hline mTcCIR114 & CAGATGAATGGAATAACTT & GCATGAACACAAACACAC & 207 & (TC)9(TG)5 G (TG)4 & 48,7 & 9 \\
\hline mTcCIR119 & TGGACTTGTGCTGGAAC & GCAAGAAATAAAATAGGAAC & 123 & $(\mathrm{AG}) 12$ & 47,8 & 5 \\
\hline mTcCIR140 & GATTCATAGTGGAAACACAGT & GGAAAACAGAGAGGAAGAGT & 104 & (CA)07 & 48,1 & 3 \\
\hline mTcCIR145 & CAGACTTCCAACTCAAAACT & TGAGAATAGATGGACCGAT & 117 & (CT) 17 & 49,7 & 9 \\
\hline mTcCIR153 & GCCTCTCACACCATTATCTG & TACATTCATTACTTCACTGCTG & 217 & (TC)09 & 50,1 & 3 \\
\hline mTcCIR155 & CTTGGACTATTGGAAAAC & AAGGATACAATAAGGTAAATAC & 274 & (TC) 12 & 46,5 & 10 \\
\hline mTcCIR184 & GGTTTTCTAGCTCCTCC & AGGAAAGAATGACTCATACTA & 139 & $(\mathrm{CA}) 8(\mathrm{CT}) 13$ & 48,2 & 1 \\
\hline mTcCIR185 & ATCCCCCTGCCTAAAGAG & CCTGAATGAAGTAAGACCCAAT & 142 & $(\mathrm{CA}) 18$ & 50 & 3 \\
\hline mTcCIR198 & TGGGACCATAAGGAAATC & CCCAGGTGAAGTAAGACA & 186 & $(\mathrm{CA}) 3 \mathrm{TA}(\mathrm{CA}) 6$ & 46,3 & 3 \\
\hline mTcCIR218 & TGACCAAGGAAGCTCTC & GGTGGGAAAGGTGGTA & 187 & (CT) 11 & 48,9 & 8 \\
\hline mTcCIR240 & CATACCTACTACTGCTCTCT & AGTGATTTATGGGACTTT & 158 & $(\mathrm{CT}) 22$ & 46,5 & 2 \\
\hline mTcCIR286 & GTTCTGCTTCATCTGTTTA & TTCAACCCACAACCAT & 119 & $(\mathrm{CT}) 18$ & 46,2 & 1 \\
\hline mTcCIR287 & TCCTTTCTGTTTGTTCCT & TTATCCGTGTCTCCTTCT & 301 & (TC)9 & 48,2 & 9 \\
\hline mTcCIR293 & GAAAGGCCATATTGATGCT & СТАТTТССАСАСТСААТТССА & 266 & $(\mathrm{AT}) 9$ & 55,2 & 9 \\
\hline mTcCIR294 & GGGAGAGACACAGAGAGCTA & GCCACTTTCTCCATCGT & 128 & $(\mathrm{AG}) 14$ & 54,4 & 9 \\
\hline mTcCIR302 & CTGTAACCAACCCTAAAGAAAA & AGTTGAATGTTGGCCCTT & 269 & $(\mathrm{AT}) 8$ & 55,4 & 1 \\
\hline mTcCIR304 & GTGCTGGTGGTGAAGGA & GGCTTCGAGGAAGGGT & 219 & $(\mathrm{TA}) 8$ & 56,1 & 1 \\
\hline mTcCIR310 & GGGGATACTTGACCTCTGTT & GCTGGACCTAAAACGCA & 176 & (CT)12 & 55,6 & 8 \\
\hline mTcCIR316 & AAAAGCATCTCTCCCCA & AGCTGTCCATGCTCCTT & 137 & (CT)15 & 53,9 & 3 \\
\hline mTcCIR331 & CCСCTCCATTTGGTTTC & CATGACCTCCGCCTGT & 222 & $(\mathrm{CT}) 11$ & 56,1 & 1 \\
\hline mTcCIR337 & ACGAAGCCGTAACTTGG & TGCAGGACTCTCTGTCACT & 208 & $(\mathrm{GGA}) 5$ & 54,3 & 6 \\
\hline mTcCIR342 & CCGGAAAACATTGAACAC & TGGGCTCACCCTTTCT & 223 & $(\mathrm{CT}) 10$ & 54,7 & 1 \\
\hline mTcCIR353 & TGAGTTGAATCACTTTGGCT & TGTTGGACGGGTTGTTC & 250 & (TGT) & 55,9 & 3 \\
\hline mTcCIR356 & GGGGTTGCTTTCTGCTT & AAAACTTGGCGGAGGAG & 163 & (TC)6 & 56,2 & 1 \\
\hline mTcCIR359 & TCGAGATACGCAAACGAA & TGGACATTGCGAAAACC & 188 & (TC)7 & 56,3 & 4 \\
\hline mTcCIR382 & AAAGAGCGAAAGCAGGG & CCACACCAAGGAGCGT & 245 & $(\mathrm{AG}) 16$ & 56,4 & 8 \\
\hline mTcCIR419 & ATTTGCCCTTCTCGCTC & CAGCAGCACGCCTAAAC & 169 & $(\mathrm{CCG}) 8$ & 56,4 & 1 \\
\hline mTcCIR429 & GGGGATACATCTTCTGCTCT & TTTATTGGTTTCCCGTCC & 177 & (CT) 12 & 55,8 & 9 \\
\hline mTcCIR430 & CGAAGGAAAGGAAGTAGAATAAG & CGTGGCTTCGATGAGTT & 206 & $(\mathrm{AG}) 10$ & 55,6 & 2 \\
\hline mTcCIR470 & TCGATCTCTTTCCATTTTgT & AAAAGGTTGCCCATATCC & 247 & (AT) 12 & 54,8 & 1 \\
\hline mTcCIR471 & AGCTGACTTGGCACCTTT & TGGGTTTGCCATTGTTC & 150 & $(\mathrm{AC}) 9$ & 55,8 & 8 \\
\hline mTcCIR472 & TGGTGATGCTTTTGGAGA & CACCGCTGTTCTTTTGG & 251 & (GA) 13 & 56 & 8 \\
\hline mTcCIR550 & CATGAGGAATGATTGGGA & ACATGCCtGGATTGATTTAC & 231 & $(\mathrm{AC}) 9$ & 54,9 & 1 \\
\hline mTcCIR556 & ACACTTATAGACGGAGCACTAAA & CGCTCTTACATTGAAAtcTTG & 259 & $(\mathrm{AT}) 8$ & 55,1 & 5 \\
\hline mTcCIR560 & TAGTCGCACATAGCCGAG & TTGGGAACAAGCCCC & 147 & (TA) 8 & 55,9 & 5 \\
\hline mTcCIR563 & CTCAACACACTTAGCTCAACC & TGAAGAATGTGATTACGAAGG & 211 & (AT) 10 & 55,1 & 6 \\
\hline
\end{tabular}

A literatura mostra T. cacao como uma espécie promissora quando relacionada a estudos envolvendo genômica comparativa com a espécie $T$. grandiflorum. As duas espécies mantêm um alto índice de regiões genéticas conservadas, devido à alta porcentagem de marcadores de cacaueiro amplificados em cupuaçuzeiro. Esse fato é justificado ao fato que espécies filogeneticamente próximas apresentam homologia das sequências flanqueadoras aos locos microssatélites, permitindo assim sua transferibilidade. Kuhn et al. (2010), encontraram em seu trabalho $87 \%$ de transferibilidade de marcadores entre estas espécies. Segundo os autores, a conservação de sequências entre as duas espécies é significativa e que a genômica comparativa entre cacaueiro e cupuaçuzeiro pode levar a resultados promissores na busca de cultivares que apresentem diversas características de interesse agronômico. A transferibilidade de marcadores microssatélites entre espécies de um mesmo gênero ou de uma mesma família tem sido observada em plantas tropicais (Chase et al., 1996; Dayanandan et al., 1997; Sousa et al., 2018).

Foram testadas duas funções de mapeamento, Haldane e Kosambi, sendo que não houve diferença 
Tabela 5. Transferibilidade dos 30 marcadores específicos de cupuaçu cedidos pela EMBRAPA/CPATU nos diferentes genótipos de cacau

\begin{tabular}{|c|c|c|c|c|c|}
\hline $\begin{array}{l}\text { Marcador/ } \\
\text { Genótipo }\end{array}$ & Criollo & Sca6 & ICS1 & SIC864 & CCN51 \\
\hline Tg04 & + & - & + & + & + \\
\hline Tg05 & + & + & + & + & + \\
\hline Tg09 & + & + & + & + & - \\
\hline Tg11 & + & + & + & + & - \\
\hline Tg13 & + & + & + & + & + \\
\hline Tg17 & + & + & + & + & + \\
\hline Tg20 & + & + & - & + & - \\
\hline Tg21 & + & + & + & - & + \\
\hline Tg30 & + & + & + & - & + \\
\hline Tg31 & + & + & + & + & + \\
\hline Tg39 & - & - & - & - & - \\
\hline Tg43 & - & - & - & - & - \\
\hline Tg44 & + & + & + & + & - \\
\hline Tg47 & + & + & + & + & + \\
\hline $\operatorname{Tg} 48$ & + & + & + & - & + \\
\hline Tg54 & + & + & + & + & - \\
\hline Tg62 & + & + & + & + & + \\
\hline Tg64 & + & + & + & + & + \\
\hline Tg65 & + & + & + & + & + \\
\hline Tg70 & + & + & + & + & + \\
\hline Tg71 & + & + & + & + & + \\
\hline Tg72 & + & + & + & + & + \\
\hline Tg76 & - & + & + & + & + \\
\hline Tg77 & + & + & + & + & + \\
\hline Tg88 & + & + & + & + & + \\
\hline Tg89 & + & + & + & + & + \\
\hline Tg90 & - & - & - & - & - \\
\hline Tg102 & + & + & + & + & + \\
\hline Tg108 & + & + & + & + & + \\
\hline Tg113 & + & + & + & + & - \\
\hline
\end{tabular}

(+) Apresentaram transferibilidade; (-) Não apresentaram transferibilidade. significativa entre as duas no resultado final, assumindo-se o resultado proposto pela função Kosambi. O mapeamento parcial foi realizado a partir de 36 marcadores incluindo 13 SSRs do cacaueiro e 23 SSRs do cupuaçuzeiro todos genotipados pela EMBRAPA/CPATU-PA. A matriz de genotipagem foi transformada para ser utilizada de acordo com a segregação dos alelos para uma população $\mathrm{CP}$, ou seja, populações que são provenientes de genitores heterozigotos com fase de ligação dos locos originalmente desconhecida. A análise de segregação dos 36 locos está representada na Tabela 7, que identifica em números como foi realizada a distribuição dos alelos na população para cada marcador.

Os marcadores mTgM11, mTgM48 e mTcCIR182 apresentaram distorção de segregação. A literatura a respeito disso é bem diversa, alguns autores são a favor da inclusão de tais marcadores na construção de mapas (Lefebvre et al., 2002), outros preferem a exclusão total dos mesmos (Bearzoti, 2000) por produzirem, em alguns casos, um falso positivo. Nesse trabalho estes marcadores foram incluídos no processo, visto que não foi constatada mudança significativa no resultado final. Foram realizados testes com as duas situações e ambas apresentaram resultados similares. Um total de 11 marcadores não se uniu aos grupos de ligação. O mapa genético de $T$. grandiflorum foi construído então só com base em 25 marcadores, onde, nove eram do cacaueiro e 16 marcadores do cupuaçuzeiro, e foram formados sete grupos de ligação, com cobertura total de 644,5 cM, cinco desses grupos correspondem aos grupos de ligação do cacaueiro, os grupos GL4 e GL5 no mapa proposto correspondem ao GL4 do mapa genético do cacaueiro. Os grupos de ligação

Tabela 6. Marcadores SSR-EST específicos de cupuaçu cedidos pelo CENARGEN, com amplificação em cacau e nos genótipos de cupuaçu CP174 e CP1074

\begin{tabular}{|c|c|c|c|c|c|c|c|c|c|}
\hline \multicolumn{3}{|c|}{ SSR-EST/CENARGEN } & \multicolumn{2}{|c|}{ Genót. Cupuaçu } & \multicolumn{5}{|c|}{ Genótipos Cacau } \\
\hline Nome & Num allelos & Allelos & 174 & 1074 & Criollo(B97/61B2) & Scavina 6 & ICS 1 & SIC864 & CCN51 \\
\hline C_432 & $2(\mathrm{AB})$ & $(\mathrm{AB})$ & $\mathrm{AB}$ & $\mathrm{AB}$ & $\mathrm{AB}$ & $\mathrm{AB}$ & $\mathrm{AB}$ & $\mathrm{AB}$ & $\mathrm{AB}$ \\
\hline C_168 & $3(\mathrm{~A}-\mathrm{B}-\mathrm{C})$ & $(\mathrm{A}-\mathrm{B}-\mathrm{C})$ & $\mathrm{BC}$ & $\mathrm{BC}$ & $\mathrm{AC}$ & $\mathrm{AC}$ & $\mathrm{AC}$ & $\mathrm{AC}$ & $\mathrm{AC}$ \\
\hline C_4949 & $2(\mathrm{~A}-\mathrm{B})$ & $(\mathrm{A}-\mathrm{B})$ & $\mathrm{AB}$ & $\mathrm{AB}$ & $\mathrm{AB}$ & AA & AA & AA & AA \\
\hline C_295 & 4(A-B-C-D) & (A-B-C-D) & $\mathrm{BD}$ & $\mathrm{BD}$ & $\mathrm{AC}$ & $\mathrm{AC}$ & $\mathrm{AC}$ & AA & $\mathrm{AC}$ \\
\hline C_432 & $3(\mathrm{~A}-\mathrm{B}-\mathrm{C})$ & $(\mathrm{A}-\mathrm{B}-\mathrm{C})$ & $\mathrm{AB}$ & $\mathrm{AB}$ & $\mathrm{BC}$ & $\mathrm{AB}$ & $\mathrm{n}$ & $\mathrm{AB}$ & $\mathrm{BC}$ \\
\hline C_180 & $2(\mathrm{~A}-\mathrm{B})$ & $(\mathrm{A}-\mathrm{B})$ & $\mathrm{AB}$ & AA & & & & & \\
\hline C_203A & $2(\mathrm{~A}-\mathrm{B})$ & $(A-B)$ & $A B$ & $\mathrm{AB}$ & AA & $\mathrm{AA}$ & AA & AA & $\mathrm{AB}$ \\
\hline C_203B & $2(\mathrm{~A}-\mathrm{B})$ & $(A-B)$ & $\mathrm{AB}$ & $\mathrm{AB}$ & $\mathrm{AA}$ & $\mathrm{AA}$ & $\mathrm{AB}$ & & \\
\hline C_1251 & $2(\mathrm{~A}-\mathrm{B})$ & $(A-B)$ & $\mathrm{AB}$ & $\mathrm{BB}$ & & & & & \\
\hline
\end{tabular}




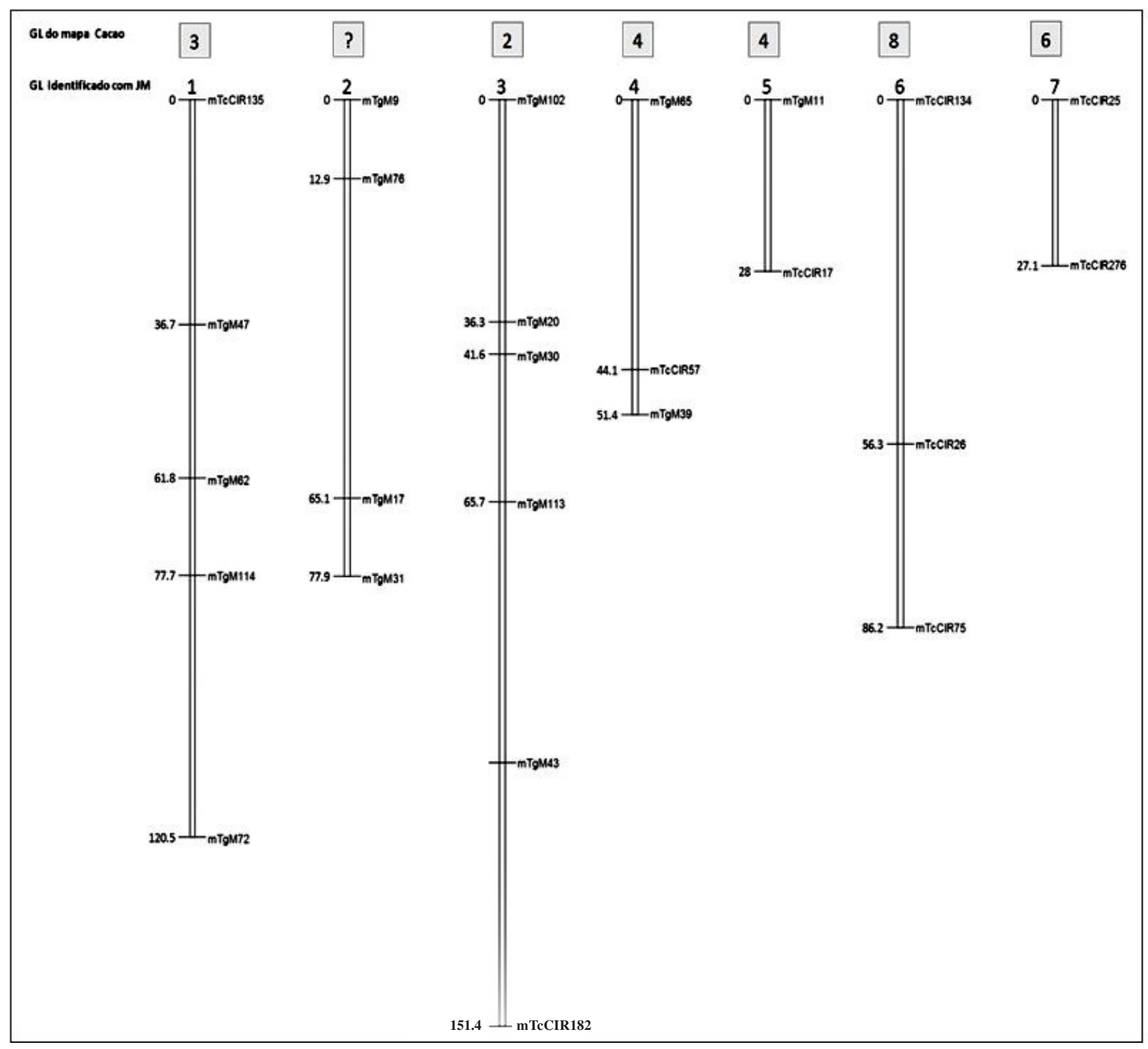

Figura 3. Mapa genético do cruzamento CP174 x CP1074 com nove SSRs de cacau e 16 SSRs de cupuaçu. A linha acima representa a correspondência estabelecida com SSRs de cacau já posicionados no mapa genético do cacaueiro

apresentaram grande diferença em relação aos seus comprimentos variando do menor grupo (GL7) que apresentou apenas dois marcadores com distância de $27.1 \mathrm{cM}$ ao maior grupo (GL3) que apresentou seis marcadores abrangendo uma distância de $151.4 \mathrm{cM}$.

Por ter um número baixo de marcadores, este mapa precisa ser saturado, com no mínimo 100 marcadores, para que se tenha uma quantidade maior de informações e a formação de novos grupos de ligação, uma vez que, a espécie apresenta um conjunto de 10 cromossomos (Alves, 2007), pois, do ponto de vista biológico, cada grupo de ligação deve representar um cromossomo da espécie. Diante disso, esse mapa pode ser considerado como uma primeira informação de um mapa genético parcial da população oriunda do cruzamento (CP174 x CP1074) da espécie $T$. grandiflorum. Foram analisados 149 pares de sequências dos microssatélites específicos de $T$. grandiflorum, com o objetivo de encontrar regiões similares conservadas entre essa espécie e T. cacao e posicionar os marcadores SSR do cupuaçuzeiro no mapa físico e no mapa genético consenso do cacaueiro 
Tabela 7. Frequência e segregação dos locos nas plantas da população de T. grandiflorum. (Tabela gerada pelo programa JoinMap)

\begin{tabular}{|c|c|c|c|c|c|c|c|c|c|c|c|c|c|c|c|c|}
\hline $\mathrm{N}^{0}$ & Loco & ee & ef & eg & $f g$ & hh & hk & $\mathbf{k k}$ & II & Im & nn & np & - & $\mathrm{X2}$ & Df & Signif. \\
\hline 1 & mTgM 11 & 50 & 17 & 24 & 26 & 0 & 0 & 0 & 0 & 0 & 0 & 0 & 25 & 21,1 & 3 & $* * * * * * * *$ \\
\hline 2 & $\mathrm{mTgM} 30$ & 41 & 38 & 32 & 29 & 0 & 0 & 0 & 0 & 0 & 0 & 0 & 2 & 2,57 & 3 & - \\
\hline 3 & $\mathrm{mTgM} 43$ & 29 & 43 & 37 & 32 & 0 & 0 & 0 & 0 & 0 & 0 & 0 & 1 & 3,2 & 3 & - \\
\hline 4 & mTgM47 & 32 & 34 & 37 & 39 & 0 & 0 & 0 & 0 & 0 & 0 & 0 & 0 & 0,82 & 3 & - \\
\hline 5 & mTcCIR26 & 29 & 48 & 34 & 31 & 0 & 0 & 0 & 0 & 0 & 0 & 0 & 0 & 6,23 & 3 & - \\
\hline 6 & mTcCIR 162 & 35 & 32 & 40 & 29 & 0 & 0 & 0 & 0 & 0 & 0 & 0 & 6 & 1,94 & 3 & - \\
\hline 7 & mTcCIR75 & 29 & 41 & 34 & 29 & 0 & 0 & 0 & 0 & 0 & 0 & 0 & 9 & 2,91 & 3 & - \\
\hline 8 & mTgM77 & 0 & 0 & 0 & 0 & 35 & 60 & 45 & 0 & 0 & 0 & 0 & 2 & 4,29 & 2 & - \\
\hline 9 & mTcCIR25 & 0 & 0 & 0 & 0 & 29 & 65 & 36 & 0 & 0 & 0 & 0 & 12 & 0,75 & 2 & - \\
\hline 10 & m Tg M 88 & 0 & 0 & 0 & 0 & 31 & 73 & 33 & 0 & 0 & 0 & 0 & 5 & 0,65 & 2 & - \\
\hline 11 & mTcCIR 182 & 0 & 0 & 0 & 0 & 30 & 93 & 2 & 0 & 0 & 0 & 0 & 17 & 42,31 & 2 & $* * * * * * *$ \\
\hline 12 & mTgM102 & 0 & 0 & 0 & 0 & 37 & 74 & 30 & 0 & 0 & 0 & 0 & 1 & 1,04 & 2 & - \\
\hline 13 & $\mathrm{mTgM} 108$ & 0 & 0 & 0 & 0 & 25 & 68 & 48 & 0 & 0 & 0 & 0 & 1 & 7,68 & 2 & $* *$ \\
\hline 14 & $\mathrm{mTgM} 113$ & 0 & 0 & 0 & 0 & 35 & 68 & 39 & 0 & 0 & 0 & 0 & 0 & 0,48 & 2 & - \\
\hline 15 & mTgM48 & 0 & 0 & 0 & 0 & 0 & 60 & 82 & 0 & 0 & 0 & 0 & 0 & 98,11 & 2 & $* * * * * * *$ \\
\hline 16 & $\mathrm{mTgM} 20$ & 0 & 0 & 0 & 0 & 0 & 0 & 0 & 68 & 72 & 0 & 0 & 2 & 0,11 & 1 & - \\
\hline 17 & mTgM54 & 0 & 0 & 0 & 0 & 0 & 0 & 0 & 62 & 80 & 0 & 0 & 0 & 2,28 & 1 & - \\
\hline 18 & mTcCIR134 & 0 & 0 & 0 & 0 & 0 & 0 & 0 & 70 & 63 & 0 & 0 & 9 & 0,37 & 1 & - \\
\hline 19 & mTcCIR 276 & 0 & 0 & 0 & 0 & 0 & 0 & 0 & 64 & 68 & 0 & 0 & 10 & 0,12 & 1 & - \\
\hline 20 & mTcCIR 12 & 0 & 0 & 0 & 0 & 0 & 0 & 0 & 59 & 76 & 0 & 0 & 7 & 2,14 & 1 & - \\
\hline 21 & mTcCIR 124 & 0 & 0 & 0 & 0 & 0 & 0 & 0 & 58 & 57 & 0 & 0 & 27 & 0,01 & 1 & - \\
\hline 22 & mTgM89 & 0 & 0 & 0 & 0 & 0 & 0 & 0 & 64 & 63 & 0 & 0 & 15 & 0,01 & 1 & - \\
\hline 23 & mTgM09 & 0 & 0 & 0 & 0 & 0 & 0 & 0 & 0 & 0 & 63 & 77 & 2 & 1,4 & 1 & - \\
\hline 24 & $\mathrm{mTgM} 13$ & 0 & 0 & 0 & 0 & 0 & 0 & 0 & 0 & 0 & 65 & 76 & 1 & 0,86 & 1 & - \\
\hline 25 & mTgM 17 & 0 & 0 & 0 & 0 & 0 & 0 & 0 & 0 & 0 & 76 & 66 & 0 & 0,7 & 1 & - \\
\hline 26 & $\mathrm{mTgM} 31$ & 0 & 0 & 0 & 0 & 0 & 0 & 0 & 0 & 0 & 70 & 72 & 0 & 0,03 & 1 & - \\
\hline 27 & mTgM39 & 0 & 0 & 0 & 0 & 0 & 0 & 0 & 0 & 0 & 64 & 69 & 9 & 0,19 & 1 & - \\
\hline 28 & mTgM62 & 0 & 0 & 0 & 0 & 0 & 0 & 0 & 0 & 0 & 86 & 56 & 0 & 6,34 & 1 & $* *$ \\
\hline 29 & mTgM65 & 0 & 0 & 0 & 0 & 0 & 0 & 0 & 0 & 0 & 60 & 80 & 2 & 2,86 & 1 & $*$ \\
\hline 30 & $\mathrm{mTgM} 72$ & 0 & 0 & 0 & 0 & 0 & 0 & 0 & 0 & 0 & 67 & 43 & 32 & 5,24 & 1 & $* *$ \\
\hline 31 & mTgM76 & 0 & 0 & 0 & 0 & 0 & 0 & 0 & 0 & 0 & 78 & 64 & 0 & 1,38 & 1 & - \\
\hline 32 & mTcCIR 17 & 0 & 0 & 0 & 0 & 0 & 0 & 0 & 0 & 0 & 70 & 55 & 17 & 1,8 & 1 & - \\
\hline 33 & mTcCIR57 & 0 & 0 & 0 & 0 & 0 & 0 & 0 & 0 & 0 & 70 & 71 & 1 & 0,01 & 1 & - \\
\hline 34 & mTcCIR 135 & 0 & 0 & 0 & 0 & 0 & 0 & 0 & 0 & 0 & 56 & 83 & 3 & 5,24 & 1 & $* *$ \\
\hline 35 & mTcCIR 148 & 0 & 0 & 0 & 0 & 0 & 0 & 0 & 0 & 0 & 72 & 58 & 12 & 1,51 & 1 & - \\
\hline
\end{tabular}

Loco: Nome do marcador; (-) Indivíduos que não apresentaram segregação para o marcador; $\mathbf{X}^{2}$ : Valor de qui-quadrado; Df: Graus de liberdade; Signif.: Indicativo proporcional de diferença entre a frequência dos genótipos esperada e a frequência observada, traduzindo a importância da distorção na segregação.

(Allegre et al., 2011), cujas sequências estão disponíveis no banco de dados do genoma do cacaueiro (na versão V1). A Tabela geral com o resultado dos blast no genoma do cacaueiro (positivos com dois primers, positivo com apenas um primer e negativo sem alinhamento) está apresentada na Tabela 8. Do conjunto analisado, 20 apresentaram alinhamento completo com sequências (forward e reverse), assim, dos 14 marcadores de origem EST, oito pares apresentaram similaridade nas duas sequências de primers (57.14\%), ressaltando que essas são sequências de regiões expressas conservadas conhecidas (Gupta; Rustgi, 2004) e tendem a se alinhar mais facilmente.
Em contrapartida, de 135 marcadores originados a partir de DNA genômico, apenas 12 marcadores apresentaram similaridade completa com o genoma do cacaueiro $(8.8 \%)$. Isso vem, provavelmente porque a parte sequenciada do genoma V1 do cacaueiro representa somente $75 \%$ do total do seu genoma predito (Argout et al., 2010). Um novo sequenciamento do genoma do cacaueiro (V2) já está disponível (Argout et al., 2017 e http://cocoagenome-hub.southgreen.fr/genome-browser), este cobre $96,7 \%$ dos cromossomos do cacaueiro, porém os dados apresentados aqui não foram reanalisados. 
Tabela 8. Relação total de todas sequências utilizadas para realização do blast

\begin{tabular}{|c|c|c|c|c|c|c|c|c|c|}
\hline \multicolumn{3}{|c|}{ SSRs Cupuaçu } & \multicolumn{7}{|c|}{ Resultados do Blast dos primers no Genome Browser } \\
\hline Nome & OR Sequencias & Institução & $\begin{array}{l}\text { cromos- } \\
\text { somo }\end{array}$ & Start & End & $\begin{array}{l}\text { Ampli- } \\
\text { consize }\end{array}$ & $\begin{array}{l}\mathrm{Nb} \text { hit in } \\
\text { Forward }\end{array}$ & $\begin{array}{l}\text { Nb hit in } \\
\text { Reverse }\end{array}$ & State \\
\hline cupuacu_rep_c295 & EST & CENARGEN & Tc 00 & 8666688 & 8666792 & 105 bp & 1 & 1 & OK \\
\hline $\operatorname{Tg} 20$ & Bibliotecas & CPATU & $\mathrm{Tc} 00$ & 20599290 & & & 1 & NA & \\
\hline $\operatorname{Tg} 21$ & Bibliotecas & CPATU & $\mathrm{Tc} 00$ & 20599312 & & & 1 & NA & \\
\hline $\operatorname{Tg} 60$ & Bibliotecas & CPATU & $\mathrm{Tc} 00$ & 55214224 & 55214383 & 160 & 1 & 1 & $\mathrm{OK}$ \\
\hline Tg 80 & Bibliotecas & CPATU & Tc00 & 25471238 & & & 1 & NA & \\
\hline cupuacu_rep_c692_C & EST & CENARGEN & $\operatorname{Tc} 01$ & 2959034 & 2959692 & 659 bp & 1 & 1 & OK \\
\hline Tg 102 & Bibliotecas & CPATU & $\mathrm{Tc} 01$ & 4509926 & 4510029 & $104 \mathrm{bp}$ & 1 & 1 & OK \\
\hline $\operatorname{Tg} 24$ & Bibliotecas & CPATU & $\mathrm{Tc} 01$ & 877045 & 877162 & 118 & 1 & 1 & OK \\
\hline Tg 25 & Bibliotecas & CPATU & $\mathrm{Tc} 01$ & 877140 & 877243 & 104 & 1 & 1 & OK \\
\hline Tg 96 & Bibliotecas & CPATU & $\mathrm{Tc} 01$ & 5314708 & & & 1 & NA & \\
\hline $\operatorname{Tg} 122$ & Bibliotecas & CPATU & $\mathrm{Tc} 01$ & 17971070 & & & 1 & NA & \\
\hline cupuacu_rep_c180 & EST & CENARGEN & $\mathrm{Tc} 02$ & 26334484 & & & 1 & NA & \\
\hline $\operatorname{Tg} 22$ & Bibliotecas & CPATU & $\mathrm{Tc} 02$ & 6642488 & & & 1 & NA & \\
\hline Tg 32 & Bibliotecas & CPATU & $\mathrm{Tc} 02$ & 6554703 & & & 1 & NA & \\
\hline Tg 49 & Bibliotecas & CPATU & $\mathrm{Tc} 02$ & 23881231 & 23881364 & 134 & 1 & 1 & OK \\
\hline Tg 127 & Bibliotecas & CPATU & $\mathrm{Tc} 02$ & 17861027 & & & 1 & NA & \\
\hline cupuacu_rep_c432 & EST & CENARGEN & Tc03 & 19453902 & 19460025 & 6124 bp & 1 & 1 & \\
\hline $\operatorname{Tg} 91$ & Bibliotecas & CPATU & $\mathrm{Tc} 03$ & 21985815 & 21985990 & 176 & 1 & 1 & OK \\
\hline Tg 103 & Bibliotecas & CPATU & $\mathrm{Tc} 03$ & 11485748 & 11486063 & 316 & 1 & 1 & OK \\
\hline $\operatorname{Tg} 45$ & Bibliotecas & CPATU & $\mathrm{Tc} 04$ & 20433737 & & & 1 & NA & \\
\hline cupuacu_c4949 & EST & CENARGEN & Tc05 & 4877515 & & & 1 & NA & \\
\hline cupuacu_rep_c2763 & EST & CENARGEN & $\mathrm{Tc} 05$ & 12108098 & & & 1 & NA & \\
\hline cupuacu_rep_c431C & EST & CENARGEN & $\mathrm{Tc} 05$ & 670239 & 670510 & $272 b p$ & 1 & 1 & OK \\
\hline $\operatorname{Tg} 62$ & Bibliotecas & CPATU & $\mathrm{Tc} 05$ & 1912377 & & & 1 & NA & \\
\hline cupuacu_rep_c203_A & EST & CENARGEN & Tc06 & 14402937 & 14403153 & $217 \mathrm{bp}$ & 1 & 1 & OK \\
\hline cupuacu_rep_c203_B & EST & CENARGEN & Tc06 & 14402937 & 14403153 & 217 bp & 1 & 1 & OK \\
\hline cupuacu_rep_c618 & EST & CENARGEN & Tc06 & 6992017 & 6992199 & 183 bp & 1 & 1 & OK \\
\hline $\operatorname{Tg} 48$ & Bibliotecas & CPATU & Tc06 & 15005803 & 15005967 & $165 \mathrm{bp}$ & 1 & 1 & OK \\
\hline $\operatorname{Tg} 36$ & Bibliotecas & CPATU & Tc06 & 14552135 & 14552269 & 135 & 1 & 1 & OK \\
\hline cupuacu_rep_c1251 & EST & CENARGEN & Tc07 & 1161691 & & & 1 & NA & \\
\hline Tg 107 & Bibliotecas & CPATU & Tc07 & 7770762 & & & 1 & NA & \\
\hline cupuacu_rep_c339 & EST & CENARGEN & Tc08 & 3062207 & 3062334 & $128 \mathrm{bp}$ & 1 & 1 & $\mathrm{OK}$ \\
\hline $\operatorname{Tg} 120$ & Bibliotecas & CPATU & Tc08 & 8680156 & 8680298 & 143 & 1 & 1 & OK \\
\hline Tg 134 & Bibliotecas & CPATU & Tc08 & 1421686 & 1421787 & 102 & 1 & 1 & OK \\
\hline $\operatorname{Tg} 19$ & Bibliotecas & CPATU & Tc09 & 10326010 & & & 1 & NA & \\
\hline $\operatorname{Tg} 78$ & Bibliotecas & CPATU & Tc09 & 1556773 & & & 1 & NA & \\
\hline cupuacu_rep_c1773 & EST & CENARGEN & Tc 10 & 3348576 & 3348698 & 123 bp & 1 & 1 & OK \\
\hline $\operatorname{Tg} 42$ & Bibliotecas & CPATU & Tc 10 & 760284 & 760427 & 144 & 1 & 1 & OK \\
\hline cupuacu_rep_c733 & EST & CENARGEN & & & & & NA & NA & \\
\hline $\operatorname{Tg} 04$ & Bibliotecas & CPATU & & & & & NA & NA & \\
\hline Tg 05 & Bibliotecas & CPATU & & & & & NA & NA & \\
\hline Tg 09 & Bibliotecas & CPATU & & & & & NA & NA & \\
\hline Tg 13 & Bibliotecas & CPATU & & & & & NA & NA & \\
\hline Tg 17 & Bibliotecas & CPATU & & & & & NA & NA & \\
\hline Tg 30 & Bibliotecas & CPATU & & & & & NA & NA & \\
\hline Tg 31 & Bibliotecas & CPATU & & & & & NA & NA & \\
\hline Tg 39 & Bibliotecas & CPATU & & & & & NA & NA & \\
\hline $\operatorname{Tg} 43$ & Bibliotecas & CPATU & & & & & NA & NA & \\
\hline $\operatorname{Tg} 44$ & Bibliotecas & CPATU & & & & & NA & NA & \\
\hline Tg 48 & Bibliotecas & CPATU & & & & & NA & NA & \\
\hline $\operatorname{Tg} 62$ & Bibliotecas & CPATU & & & & & NA & NA & \\
\hline $\operatorname{Tg} 64$ & Bibliotecas & CPATU & & & & & NA & NA & \\
\hline $\operatorname{Tg} 65$ & Bibliotecas & CPATU & & & & & NA & NA & \\
\hline Tg 70 & Bibliotecas & CPATU & & & & & NA & NA & \\
\hline Tg 71 & Bibliotecas & CPATU & & & & & NA & NA & \\
\hline
\end{tabular}


Continuação Tabela 8

\begin{tabular}{|c|c|c|c|c|}
\hline Tg 72 & Bibliotecas & CPATU & NA & NA \\
\hline $\operatorname{Tg} 76$ & Bibliotecas & CPATU & NA & NA \\
\hline Tg 77 & Bibliotecas & CPATU & NA & NA \\
\hline Tg 88 & Bibliotecas & CPATU & NA & NA \\
\hline Tg 89 & Bibliotecas & CPATU & NA & NA \\
\hline Tg 90 & Bibliotecas & CPATU & NA & NA \\
\hline Tg 108 & Bibliotecas & CPATU & NA & NA \\
\hline Tg 113 & Bibliotecas & CPATU & NA & NA \\
\hline Tg 114 & Bibliotecas & CPATU & NA & NA \\
\hline Tg 115 & Bibliotecas & CPATU & NA & NA \\
\hline Tg 116 & Bibliotecas & CPATU & NA & NA \\
\hline Tg 117 & Bibliotecas & CPATU & NA & NA \\
\hline Tg 01 & Bibliotecas & CPATU & NA & NA \\
\hline Tg 02 & Bibliotecas & CPATU & NA & NA \\
\hline Tg 03 & Bibliotecas & CPATU & NA & NA \\
\hline Tg 06 & Bibliotecas & CPATU & NA & NA \\
\hline Tg 07 & Bibliotecas & CPATU & NA & NA \\
\hline Tg 08 & Bibliotecas & CPATU & NA & NA \\
\hline Tg 10 & Bibliotecas & CPATU & NA & NA \\
\hline Tg 12 & Bibliotecas & CPATU & NA & NA \\
\hline Tg 14 & Bibliotecas & CPATU & NA & NA \\
\hline Tg 15 & Bibliotecas & CPATU & NA & NA \\
\hline Tg 16 & Bibliotecas & CPATU & NA & NA \\
\hline Tg 18 & Bibliotecas & CPATU & NA & NA \\
\hline Tg 23 & Bibliotecas & CPATU & NA & NA \\
\hline Tg 26 & Bibliotecas & CPATU & NA & NA \\
\hline Tg 27 & Bibliotecas & CPATU & NA & NA \\
\hline Tg 28 & Bibliotecas & CPATU & NA & NA \\
\hline Tg 29 & Bibliotecas & CPATU & NA & NA \\
\hline Tg 33 & Bibliotecas & CPATU & NA & NA \\
\hline $\operatorname{Tg} 34$ & Bibliotecas & CPATU & NA & NA \\
\hline Tg 35 & Bibliotecas & CPATU & NA & NA \\
\hline Tg 37 & Bibliotecas & CPATU & NA & NA \\
\hline $\operatorname{Tg} 38$ & Bibliotecas & CPATU & NA & NA \\
\hline $\operatorname{Tg} 40$ & Bibliotecas & CPATU & NA & NA \\
\hline Tg 41 & Bibliotecas & CPATU & NA & NA \\
\hline $\operatorname{Tg} 46$ & Bibliotecas & CPATU & NA & NA \\
\hline Tg 50 & Bibliotecas & CPATU & NA & NA \\
\hline $\operatorname{Tg} 51$ & Bibliotecas & CPATU & NA & NA \\
\hline Tg 52 & Bibliotecas & CPATU & NA & NA \\
\hline Tg 55 & Bibliotecas & CPATU & NA & NA \\
\hline $\operatorname{Tg} 56$ & Bibliotecas & CPATU & NA & NA \\
\hline Tg 57 & Bibliotecas & CPATU & NA & NA \\
\hline Tg 58 & Bibliotecas & CPATU & NA & NA \\
\hline Tg 59 & Bibliotecas & CPATU & NA & NA \\
\hline $\operatorname{Tg} 61$ & Bibliotecas & CPATU & NA & NA \\
\hline $\operatorname{Tg} 63$ & Bibliotecas & CPATU & NA & NA \\
\hline $\operatorname{Tg} 66$ & Bibliotecas & CPATU & NA & NA \\
\hline $\operatorname{Tg} 67$ & Bibliotecas & CPATU & NA & NA \\
\hline $\operatorname{Tg} 68$ & Bibliotecas & CPATU & NA & NA \\
\hline Tg 69 & Bibliotecas & CPATU & NA & NA \\
\hline Tg 73 & Bibliotecas & CPATU & NA & NA \\
\hline Tg 74 & Bibliotecas & CPATU & NA & NA \\
\hline Tg 75 & Bibliotecas & CPATU & NA & NA \\
\hline Tg 79 & Bibliotecas & CPATU & NA & NA \\
\hline Tg 81 & Bibliotecas & CPATU & NA & NA \\
\hline Tg 82 & Bibliotecas & CPATU & NA & NA \\
\hline Tg 83 & Bibliotecas & CPATU & NA & NA \\
\hline Tg 84 & Bibliotecas & CPATU & NA & NA \\
\hline
\end{tabular}


Continuação Tabela 8

\begin{tabular}{|c|c|c|c|c|}
\hline Tg 85 & Bibliotecas & CPATU & NA & NA \\
\hline Tg 86 & Bibliotecas & CPATU & NA & NA \\
\hline Tg 87 & Bibliotecas & CPATU & NA & NA \\
\hline Tg 92 & Bibliotecas & CPATU & NA & NA \\
\hline Tg 93 & Bibliotecas & CPATU & NA & NA \\
\hline Tg 94 & Bibliotecas & CPATU & NA & NA \\
\hline $\operatorname{Tg} 95$ & Bibliotecas & CPATU & NA & NA \\
\hline Tg 97 & Bibliotecas & CPATU & NA & NA \\
\hline Tg 98 & Bibliotecas & CPATU & NA & NA \\
\hline Tg 99 & Bibliotecas & CPATU & NA & NA \\
\hline Tg 100 & Bibliotecas & CPATU & NA & NA \\
\hline Tg 101 & Bibliotecas & CPATU & NA & NA \\
\hline Tg 104 & Bibliotecas & CPATU & NA & NA \\
\hline Tg 105 & Bibliotecas & CPATU & NA & NA \\
\hline Tg 106 & Bibliotecas & CPATU & NA & NA \\
\hline Tg 109 & Bibliotecas & CPATU & NA & NA \\
\hline Tg 110 & Bibliotecas & CPATU & NA & NA \\
\hline Tg 111 & Bibliotecas & CPATU & NA & NA \\
\hline Tg 112 & Bibliotecas & CPATU & NA & NA \\
\hline Tg 118 & Bibliotecas & CPATU & NA & NA \\
\hline Tg 119 & Bibliotecas & CPATU & NA & NA \\
\hline Tg 121 & Bibliotecas & CPATU & NA & NA \\
\hline Tg 123 & Bibliotecas & CPATU & NA & NA \\
\hline Tg 124 & Bibliotecas & CPATU & NA & NA \\
\hline Tg 125 & Bibliotecas & CPATU & NA & NA \\
\hline Tg 126 & Bibliotecas & CPATU & NA & NA \\
\hline Tg 128 & Bibliotecas & CPATU & NA & NA \\
\hline Tg 129 & Bibliotecas & CPATU & NA & NA \\
\hline Tg 130 & Bibliotecas & CPATU & NA & NA \\
\hline Tg 131 & Bibliotecas & CPATU & NA & NA \\
\hline Tg 132 & Bibliotecas & CPATU & NA & NA \\
\hline Tg 133 & Bibliotecas & CPATU & NA & NA \\
\hline Tg 135 & Bibliotecas & CPATU & NA & NA \\
\hline
\end{tabular}

\section{Conclusões}

As análises de transferibilidade de marcadores microssatélites entre $T$. cacao e $T$. grandiflorum mostraram uma baixa taxa de transferibilidade entre os marcadores do cacaueiro quando amplificados em cupuaçuzeiro e uma alta taxa de transferibilidade dos marcadores de cupuaçuzeiro quando amplificados em cacaueiro, indicando que a conservação de sequências entre essas duas espécies pode levar a resultados promissores na busca de cultivares que apresentem diversas características de interesse agronômico. Os marcadores microssatélites oriundos de ESTs tiveram uma taxa de transferibilidade maior que os microssatélites provenientes de regiões genômicas.

Através desse trabalho foi possível obter um Mapeamento genético parcial de $T$. grandiflorum, que servirá como referência para trabalhos futuros envolvendo mapeamento genético da espécie.

\section{Agradecimentos}

Nossos sinceros agradecimentos a todas as Instituições e pessoas que fizeram com que esse trabalho fosse concluído com êxito. Em especial a CAPES, pela concessão da bolsa de estudos a primeira autora; à UESC, CEPLAC, EMBRAPA (de Belém e Brasília) e ao CIRAD.

\section{Literatura Citada}

AIME, M. C.; PHILLIPS-MORA, W. 2005.The causal agents of witches' broom and frosty pod rot of cacao (chocolate, Theobroma cacao) form a new lineage of Marasmiaceae. Mycologia 97:1012-1022.

ALLEGRE, M. et al. 2011. Discovery and mapping of a new expressed sequence tag-single nucleotide polymorphism and simple sequence repeat panel 
for large-scale genetic studies and breeding of Theobroma cacao L. DNA Research. 13p.

ALVES, R. M. et al. 2017. Phenotypic and genotypic characterization and compatibility among genotypes to select elite clones of cupuassu. Acta Amazonica 47(13):175-184.

ALVES, R. M. et al. 2013. Diversidade genética em coleções amazônicas de germoplasma de Cupuaçuzeiro [Theobroma grandiflorum (Willd. exSpreng.) Schum.], Revista Brasileira de Fruticultura 35(3):818-828.

ALVES, R. M. et al. 2007. High levels of genetic divergence and inbreeding in populations of cupuassu (Theobroma grandiflorum). Tree Genetic Genomic 3:289-298.

ARGOUT, X. et al. 2017. The cacao Criollo genome v2.0: an improved version of the genome for genetic and functional genomics studies. BMC Genomics 18:730.

ARGOUT, X. et al. 2010. The genome of Theobroma cacao. Nature Genetics 4:101-108.

BEARZOTI, E. 2000. Mapeamento de QTL. In: Pinheiro, J. B.; Carneiro, I. F. ed. Análise e QTL no melhoramento de plantas. Goiânia, GO, FUNAPE. pp.63-224.

BROWN, S. J. et al. 2005. Resistance gene mapping for witches'broom disease in Theobroma cacao L. in an F2 population using SSR markers and candidate genes. Journal American Society Horticulture Science 130(3):366-372.

CHASE, M. R.; KESSELI, R.; BAWA, K. S. 1996. Microsatellite markers for population and conservation genetics of tropical tres. American Journal of Botany 83:51-57.

CRESTE, S.; TULMAN, A.; FIGUEIRA, A. 2001. Detection of single sequence repeat polymorphisms in denaturing polyacrylamide sequencing gels by silver staining. Plant Molecular Biology Reporter 19(4):299-306.

DAYANANDAN, S.; BAWA, K. S.; KESSELI, R. 1997. Conservation of microsatellites among tropical trees (Leguminosae). American Journal of Botany 84:1658-1663.

FALEIRO, F. G. et al. 2006. MappingQTLs for
Witches' Broom (Crinipellis perniciosa) Resistance in cacao (Theobroma cacao L.). Euphytica 149:227-235.

FERRAZ DOS SANTOS, L. et al. 2016. First microsatellite markers developed from cupuassu ESTs: application in diversity analysis and crossspecies transferability to cacao. Plos One 11(3):1-19.

GRAMACHO, K. P. et al. 2007. Characterization of microsatellites in the fungal plant pathogen Crinipellis perniciosa. Molecular Ecology Notes 7:153-155.

GUPTA, P. K.; RUSTGI, S. 2004. Molecular markers from the transcribed/expressed region of the genome in higher plants. Functional and Integrative Genomics 4:139-162.

HANCOCK, J. M. 2000. Microsatellites and other simple sequences: genomic context and mutational mechanisms. In: Goldstein, D. B.; Schlotterer, C. ed. Microsatellites. Evolution and applications. New York, Oxford University Press. pp.1-9.

HOMMA, A. K. O.; CARVALHO, R. A.; MENEZES, A. J. E. A. 2001. Extrativismo e plantio racional de cupuaçuzeiros no sudeste paraense: a transição inevitável. (Compactdisc). In: Congresso Brasileiro de Economia e Sociologia Rural, 39, Recife, PE. Anais. Brasília, DF, SOBER.

INTERNATIONAL COCOA ORGANIZATION ICCO. 2014. Annual Report 2011/2012. 70p.

KUHN, D. N. et al. 2010. Evaluating Theobroma grandiflorum for comparative genomic studies with Theobroma cacao. Tree Genetics \& Genomes 6:783-792.

KULEUNG, C. P. S.; BAENZIGER, I.; DWEIKAT. 2004. Transferability of SSR markers among wheat, rye, and triticale. Theoretical Applied Genetics 108:1147-1150.

LANAUD, C. et al. 1995. A genetic linkage map of Theobroma cacao L. Theoretical and Applied Genetics 91(6-7):987-993.

LEFEBVRE, V. et al. 2002. Towards the saturation of the pepper linkage map by alignment of three intraspecific maps including known-function genes. Genome 45:839-854. 
LOPES J. R. M.; LUZ, E. M. N.; BEZERRA, J. L. 2001. Suscetibilidade do cupuaçuzeiro e outras espécies vegetais a isolados de Crinipellis perniciosa obtidos de quatro hospedeiros diferentes no sul da Bahia. Fitopatologia Brasileira 26(3):601-605.

MOTAMAYOR, J. C. et al. 2013. The genome sequence of the most widely cultivated cacao type and its use to identify candidate genes regulating pod color. Genome Biology 14:53

PEAKALL, R. et al. 1998. Cross-species amplification of soybean (Glycine max) simple-sequencerepeats (SSRs) within the genus and the other legume genera. Molecular Biology and Evolution 15:1275-1287.

PEREIRA, J. L. et al. 1989. Primeira ocorrência de vassoura de bruxa na principal região produtora de cacaueiro do Brasil. Agrotrópica (Brasil) 1:79-81.

PUGH, T. et al. 2004. A new cacao linkage map based on codominant markers: development and integration of 201 new microsatellite markers. Theoretical and Applied Genetics 108:1151-1161.

RISTERUCCI, A. M. et al. 2000. A high-density linkage map of Theobroma cacao L. Theoretical and Applied Genetics 10:948-955.

SCHNELL, R. J. et al. 2007. Development of a marker assisted selection program for cacao. Phytopathology 97(12):1664-1669.

SILVA, S. D. V. M. et al. 2003. Cacao resistance to Crinipellis perniciosa: diallelic crosses increase genes for resistance. In: International Congress of Plant Pathology, 8th. Christchurch Addendum to Abstracts of Offered Papers, Christchurch New Zealand 8th ICPP. p.8.

SOUSA, L. L. et al. 2018. Transferibilidade de marcadores microssatélites em espécies de Psidium. Ciência \& Tecnologia (Brasil) $10(2$ Número especial.)

VAN OOIJEN, J. W. 2006. JoinMAP V4.1, software for the calculation of genetic maps in experimental. 